IZA DP No. 7948

Adjusting Your Dreams?

The Effect of School and Peers on Dropout Behaviour

Dominique Goux

Marc Gurgand

Eric Maurin

February 2014

Forschungsinstitut zur Zukunft der Arbeit Institute for the Study of Labor 


\title{
Adjusting Your Dreams? The Effect of School and Peers on Dropout Behaviour
}

\author{
Dominique Goux \\ CREST
}

Marc Gurgand

Paris School of Economics

and IZA

\section{Eric Maurin}

Paris School of Economics

and IZA

\section{Discussion Paper No. 7948 \\ February 2014}

\author{
IZA \\ P.O. Box 7240 \\ 53072 Bonn \\ Germany \\ Phone: +49-228-3894-0 \\ Fax: +49-228-3894-180 \\ E-mail: iza@iza.org
}

\begin{abstract}
Any opinions expressed here are those of the author(s) and not those of IZA. Research published in this series may include views on policy, but the institute itself takes no institutional policy positions. The IZA research network is committed to the IZA Guiding Principles of Research Integrity.

The Institute for the Study of Labor (IZA) in Bonn is a local and virtual international research center and a place of communication between science, politics and business. IZA is an independent nonprofit organization supported by Deutsche Post Foundation. The center is associated with the University of Bonn and offers a stimulating research environment through its international network, workshops and conferences, data service, project support, research visits and doctoral program. IZA engages in (i) original and internationally competitive research in all fields of labor economics, (ii) development of policy concepts, and (iii) dissemination of research results and concepts to the interested public.
\end{abstract}

IZA Discussion Papers often represent preliminary work and are circulated to encourage discussion. Citation of such a paper should account for its provisional character. A revised version may be available directly from the author. 


\section{ABSTRACT \\ Adjusting Your Dreams? The Effect of School and Peers on Dropout Behaviour ${ }^{1}$}

At the end of middle school, many low achieving students have to abandon hope of getting into selective high-school programs, which may be a source of disappointment and eventually lead them to dropout from high-school. Based on a randomized controlled trial, this paper shows that low-achieving students' aspirations can be made more realistic through a series of meetings facilitated by the school principals and that more realistic aspirations are followed by a significant reduction in grade repetition and high-school dropout. Building on detailed information on friendship networks within classes, we also find evidence that improved outcomes in treated classes encompass improved social interactions between low achieving students and their high achieving classmates.

JEL Classification: $\quad$ I21, I24, J18

Keywords: school dropout, tack choices, school aspiration, social networks

Corresponding author:

Marc Gurgand

Paris School of Economics

48, boulevard Jourdan

75014 Paris

France

E-mail: gurgand@pse.ens.fr

\footnotetext{
${ }^{1}$ This research was supported by a grant from the French Experimental Fund for the Youth. We are very grateful for the support of the schools and administrative teams from the Rectorat de Versailles. We thank Adrien Bouguen, Bastien Michel and the many J-Pal Europe research assistants that worked on this project. We also thank seminar participants at Paris School of Economics, London School of Economics, CREST (Paris), Tinbergen Institute (Amsterdam), Louvain-la-Neuve University, Aarhus University, University of Warwick, Austin-Bergen Education and Labor Workshop, BergenStavanger Labor Workshop and fourth IWAEE conference in Cantazaro.
} 


\section{Introduction}

School dropout is a subject of major concern in most developed countries. High-school dropouts experience considerably larger unemployment rates than their better educated peers and are much more exposed to poverty and delinquency (Belfield and Levin, 2007). In periods of economic stagnation, the gap between dropouts and the rest of the youths tends to increase over time, leading to rising polarization and concern for social cohesion.

There are many potential sources of dropout, pertaining to the individual, the school and the social environment (Rumberger and Lim, 2008, Murnane, 2013). However, the mechanisms leading to dropout are not completely understood. Much of the economic literature views education as an investment, involving the comparison of immediate costs and anticipated gains. Students drop out from school when the anticipated rewards from staying in school become too low compared to the financial or psychological costs from doing so (Eckstein and Wolpin, 1999). In this set-up, dropout may reflect an accurate evaluation of the costs and benefits of staying in education, but it may also be driven by students underestimating the rewards from obtaining a degree or simply ignoring the future consequences of their decisions (Oreopoulos, 2007). There is growing evidence that perceived returns to schooling are low compared to actual returns and that improved knowledge of returns to schooling may contribute to improving school attendance, at least in developing countries (Nguyen, 2008, Jensen, 2010).

In this article we explore another basic cause of high-school dropout, namely the discrepancy between students' educational aspirations (what they hope to do) and the type of high-school program they are allowed to get into, given their academic record. In many developed countries, a uniform schooling system terminates at adolescence, and gives place to a highly stratified system of schools and tracks which typically involves a prestigious academic track and a complex system of vocational schools, with a number of specialities and 
locations. $^{2}$ Given that only the best students can get access to the most academic tracks, such a system may be a source of deep disappointment for many students, especially those whose academic results are weak and whose information is incomplete about available options and mechanisms of assignment of students to tracks. Many find themselves obliged to choose among tracks which they never planned to attend, and this may eventually lead them to dropout from education.

This paper reports the results of a large scale randomized experiment showing that a simple program of meetings facilitated by school principals and targeted at low-achieving students can induce students' and families' education expectations to become more realistic and contribute to a significant reduction in grade repetition as well as dropout during highschool. In 37 middle-schools of Paris suburban areas, mostly in deprived neighborhood, school principals were asked to preselect the $25 \%$ lowest performing students in ninth grade, the last grade of uniform education in France, before irreversible track choices have to be made. After the lists of students were filled, we randomized about half of the classes, in which parents of preselected students were invited by school principals to attend two meetings on track choices during the second term. At the end of the third term, students are either allowed to enter the academic three-year high school, or must rank a choice of four vocational tracks into a centralized allocation system, where acceptance is based on average academic performance in ninth grade.

At the end of the treatment year, we find that parents in the treatment group are more involved in schools, more satisfied with information, and formed educational expectations that fit better with the very low academic record of their children. Also, we find that this is reflected in their children's applications at the end of the treatment year. Building on exhaustive administrative data, we show that the proportion who include at least one 2-year

\footnotetext{
${ }^{2}$ See OECD (2008) or European commission (2013). Almost half of high-school students in OECD countries are enrolled into vocational education (OECD, 2008).
} 
vocational program in their list of possible high-school assignments increases by about 30\%, whereas the proportion who pursue strategies to end up exclusively in the more selective 3year programs decreases by about the same proportion.

This adjustment in selected student's educational aspirations is followed by very significant shifts in their actual assignments one year after the treatment. Selected students obtain more often their demanded tracks and end up less often repeating ninth grade or dropping out from high-school. Specifically, one year after the treatment, their grade repetition rate is reduced from $13 \%$ to $9 \%$ and their dropout out rate is reduced from $9 \%$ to 5\%. Two years after the intervention, we find that treated students were not induced to make choices that did not fit their taste or capacity, neither to only postpone dropout: they are now in second year of vocational education or apprenticeship by the same proportion as one year before, and they are even less dropouts. As it turns out, by inducing many students to opt for a 2-year vocational program rather than to repeat ninth grade, the intervention did not harm their education prospects, but contributed to reducing their dropout rates further.

Building on the partial population design of our experiment and on detailed information on friendship networks, we also explore whether the intervention has an influence on nonselected students. Evidence on such spillover effects is obtained only when we focus on the $20 \%$ non-selected students who have both selected friends and relatively low academic records: we find that a significant fraction of those with treated friends are induced to get into a vocational high-school just after middle-school rather than try to pursue into the academic track. These results are suggestive that students may be influenced by their classmates, but only when they closely interact with them and face similar education alternatives.

Because we measured friendship networks both at the start and the end of the treatment year, we can also show that the intervention induced significant changes in the composition of selected students' friendship networks over the year. Treated students have a more stable 
network and the composition of their network evolves towards relatively high achievers. These results are suggestive that the intervention contributed to a better integration of selected students to school and it is one channel through which it may have contributed to reducing their dropout rates.

Overall our experiment brings new evidence on the mechanisms leading to dropout and, specifically, on the role of students' aspirations. The social science literature has long emphasised the role of aspirations in shaping educational attainment, but there is still very little evidence on whether adjusting aspirations really makes a difference (Jacob and Wilder, 2011). As our intervention generates exogenous changes in students' aspirations without affecting their academic record, it provides a unique tool for exploring this issue. It shows that a reduction in the proportion of low-achieving students with unrealistic aspirations in a class (i.e., aspiring exclusively to get into a selective track) is followed by a reduction in dropout rates which is about half as large. These results are in line with the psychological literature which has long emphasized that unrealized expectations may have devastating consequences for individuals (see e.g. Gottfredson, 1981, Higgins, 1987, Walker and Pettigrew, 1984, Wheaton, 1994). Also, they are consistent with Stinebrickner and Stinebrickner (2013) who observe that overoptimistic expectations at entry into university are associated with higher dropout rates in US colleges.

By showing that a simple intervention facilitated by the school principal is able to induce a significant fraction of would-be dropouts and would-be repeaters to identify and opt for programs in which they are able to persist and pass grades, our experiment also contributes to the literature on dropout prevention policies. Many interventions involve tutoring and academic support (Dynarski et al., 2008), financial incentives (Dearden et al., 2009, Oreopoulos et al., 2009), early childhood interventions (Heckman, 2008) or, more radically, compulsory schooling age (Oreopoulos, 2006 and 2007). Compared to such 
interventions, the set of meetings considered here are extremely low cost: although the school district had to define guidelines and edit a DVD displaying former students of vocational tracks, the marginal cost of the intervention is very limited, as it involves school principal's time for two meetings and the effort to invite parents.

It is likely, however, that receiving information from the school principal has been very important because of his/her credibility and of his/her knowledge of individual situations. This adds to the recent understanding of their importance for school policies. Extending the literature on the role of leaders (Bertrand and Schoar, 2003), Branch et al.(2012) and Duhey and Smith (2013) suggest that school principals have significant influence on student performance, and Griffith (2001) notes their importance in developing a welcoming school climate, especially towards families from lower socioeconomic background.

We also contribute to the literature on peer effects and social interactions. In particular, we show that the overall effect of a policy intervention may depend on the actual friendship ties between initially targeted individuals and the rest of the population. This finding is consistent with recent research on the impact of the network position of the first individuals to receive information about a new product on its eventual diffusion (Banerjee et al., 2013). Also, building on our longitudinal information on networks, we show that a simple schoolbased intervention is able to modify the strength and distribution of friendship ties across classmates over the treatment year. To the best of our knowledge, our experiment is one of the very first to provide robust evidence on the effects of a public policy intervention on friendship network composition, which represents nonetheless a potentially important channel through which policy interventions may affect behaviors (Carell et al. 2013).

The next section presents the institutional context of the experiment and specifically the rules governing track choice at the end of middle school in France. Sections 3 and 4 present 
the experimental design and data respectively. We then move to the measure of the effects of the intervention on applications at the end of the intervention year (section 5) and its effect on school status one year and two years after the intervention (section 6). Section 7 provides an analysis of spillovers and friendship network. Section 8 builds on the experiment to provide class level estimates of the effect of educational aspiration on dropout behavior and section 9 concludes.

\section{Track choices at the end of middle school: institutional context}

Middle school in France runs from grade 6 to grade 9. Students complete ninth grade the year they turn 15 or the year they turn 16 (which is also the school minimum leaving age), depending on whether they have been held back a grade before or not. The curriculum is the same in all middle schools and there is no streaming by ability.

For ninth graders, a typical week consists of 29 school hours, distributed across 11 different subjects, with a different teacher teaching each subject. Pupils stay in the same class of 20 to 30 pupils throughout the school year, and in every subject. The class is therefore a very distinct and closed entity where most of the interactions with same age children take place.

The year is divided into three terms. At the end of the last term, French ninth graders have six basic options for the next year, four within the National Education system and two outside that system. Those who decide to stay in the school system can either pursue a 3-year academic track in high school or get into a vocational school (lycée professionnel) and pursue either a 3-year or a 2-year vocational program. They also have the possibility to stay in middle-school for one additional year: each student is endowed with the right to repeat ninth grade at least one time. 
Students who do not stay in the school system can either get into an apprenticeship centre or dropout from education and training. Apprentices have the possibility to pursue the same 2-year or 3-year programs as students in a vocational school, the difference being that apprenticeship involves periods of training on the job with a specific tutor in a specific host company. Apprenticeship centres are funded by the private sector and do not depend on the National Education system. ${ }^{3}$

Students who pursue vocational studies have not only to choose a specific training institution (vocational school versus apprenticeship centre), a specific degree (2-year vs. 3year degree), but also a specific qualification: hairdressing, carpentry, cooking, bakery, sales, auto repair, etc. In the sole district of Versailles (where the experiment took place), there are about 60 different types of 3-year programs, almost the same number of 2-year programs and more than 300 apprenticeship centres.

At the end of the academic year, school principals and teachers decide who is allowed to pursue in the academic track. They base their decisions on students' academic performance during the school year. In 2010, about 60\% of French ninth graders ended up admitted in a 3year academic program. If not admitted, students can either ask to repeat ninth grade or apply for a vocational school. ${ }^{4}$ In that case, they are asked to list up to four specific choices by descending order of preference. Each possible choice corresponds to a specific qualification (plumbing, hair dressing...) in a specific school. A central assignment system (called Affelnet) builds on average marks obtained during ninth grade to rank applications and to assign as much students as possible to one of their listed choices, using a deferred acceptance algorithm (Roth, 2008). The initial outcome of the centralized assignment procedure is known early

\footnotetext{
${ }^{3}$ The French law stipulates that firms with more than 250 employees must either have 4\% (or more) apprentices in their labour force or pay additional taxes. The actual rate of apprentices in these firms is only about $1.7 \%$ and many employers have actually to pay additional taxes.

${ }^{4}$ In parallel, they can also appeal against the decision of the school. If they win, they free the slot to which they were assigned by the central system. About $1.5 \%$ of ninth graders appeal against school decision.
} 
July. Assigned students then have a few days to actually register in their new school. ${ }^{5}$ After this initial registration period, a small fraction of students remain unassigned and a more informal second round takes place during the summer where non-assigned students are asked to reformulate their choices and to apply for tracks that remained undersubscribed after the first round.

The final outcome of the assignment procedure is observed at the beginning of the subsequent academic year. In our experimental schools, a large majority of students get admitted into a high-school program, where they start either a 3-year academic (58\%), a 3year vocational (25\%) or a 2-year vocational program (3\%). In addition, only about 3\% get access to an apprenticeship centre. Finally, about 6\% drop out from education and about 6\% opt for repeating ninth grade. One year later, an additional proportion of students fail to complete the first year of their program and choose to drop out. Two years after the initial assignment procedure, the proportion of dropouts rises to about $13 \% .{ }^{6}$ One of the basic questions asked in this paper is whether it is possible to reduce these dropout rates through a school-based intervention designed to enrich students' choice set and to reduce the discrepancy between their educational aspirations and their academic aptitudes.

\section{Program and experimental design}

\subsection{School and student selection}

The experiment took place in the educational district of Versailles, which includes all suburbs located to the west of Paris, with about 5.5 million inhabitants. It is the largest French district with more than 1.1 million students, or $9 \%$ of the French total. In 2010, the district

\footnotetext{
${ }^{5} \mathrm{~A}$ small fraction of assigned students decide not to register either because they choose to get outside the education system (apprenticeship, direct entry into the labour market) or because they finally choose to repeat ninth grade (it is always possible, at each stage of the process) or because they won their appeal against the school. These non-registration free slots for non-assigned students and some of them will finally end up assigned to one of their initial choices.

${ }^{6}$ The comparable national figure is 7.5\% (Ministère de l'éducation nationale, 2011).
} 
authority has decided to start a preventive program against dropout at the end of middle school. About 50 middle-schools were invited by the district head to take part into the experiment, out of which 37 volunteered: they represent $9 \%$ of the 400 middle-schools of the district. Low income areas are over-represented in this sample: about two thirds of the volunteer schools belong to the $25 \%$ poorest neighborhoods in the district (and less than $10 \%$ belong to the $50 \%$ wealthiest). The universe of the experiment is the 4,291 ninth grade students of those 37 middle schools, in 179 classes. $^{7}$

Early in the 2010-2011 academic year, in every ninth grade class, the school principal pre-selected the students most exposed to the risk of dropping out. In December 2010, lists were final and they contained 1,130 students, representing about $25 \%$ of all ninth grade students in the experiment, and about 6 students per class. Principals were asked to rely on objective data to identify the selected students, specifically academic performance. First trimester student information confirms that selected students are academically weaker and of poorer origin than the rest of the students. For instance, half of the selected students have repeated a grade at some point, against 25\%; one third of selected students are from low income families (measured through eligibility to scholarships), compared to $23 \%{ }^{8}$

\subsection{Randomization}

Once the lists of selected students were finalized in all schools, we randomized treatment classes within each school. Half of the classes - or half plus one in case of an odd number of classes - belong to the treatment group, and randomization was stratified by number of preselected students, number of girls and number of late students in the class. In the end, we have 97 treatment and 82 control classes. Appendix Table A1 compares initial

\footnotetext{
${ }^{7}$ Special education students are excluded from the intervention because their orientation in vocational education is already determined. Eight students with missing identification numbers (one of them among selected students) are also dropped from the data.

${ }^{8}$ About $25 \%$ of families nationally are eligible to scholarships.
} 
characteristics of the two groups of selected students, in terms of parents' income, gender, grade repetition, and there are no significant differences between them.

Only the parents of selected students in the 97 treatment classes were then invited to attend the meetings facilitated by the school principal. Most of the results in this paper are based on the comparison of selected students in treated and control classes. Under the basic assumption that selected students in control classes remain unaffected by the treatment (SUTVA), this comparison provides the estimate of an intention-to-treat parameter, namely the impact of the invitation to the meetings on the outcomes of students at risk of dropping out from education. Additional results will be based on the comparison of non-selected students in the two types of classes, so as to identify potential spillover effects on these students.

\subsection{Program content}

After randomization, the principals have called each eligible family to invite them to attend two collective meetings on their child's tracking choice. Invitation does belong to the intervention because it may elicit the feeling with the parents that their input is appreciated, which may in itself improve their involvement. In a previous control trial with sixth graders families, Avvisati et al. (2011) observed that participation to school meetings are strongly improved when parents have been called directly rather than informed about the meeting by letter.

Meetings take place in the school, typically at $6 \mathrm{pm}$, between January and early April. District experts have prepared guidelines for the meetings as well as a DVD with videos showing students who explain how they perform in vocational education, although they failed in middle-school. The guidelines explain how to inform and counsel families about the complex tracking system and the application and allocation mechanism. They also suggest that the expectations of each family should be discussed in view of the actual student 
performances, and that families should be helped to adjust their expectations to those performances.

Generally, the objective of the program is to improve the information level of families regarding the choice set and the related outcomes. It also aims at involving parents from low social background into the decision, and not let their children in face of those difficult decisions.

The cost of this program is mostly related to the conception and the production of guidelines and DVDs. These are mostly fixed costs that hardly increase with the scope of the program. The schools did not receive a specific budget for this program. As the intervention consists of two collective two-hour meetings, the opportunity cost of the school principal's time is limited to a few hours, plus the time to contact parents.

\subsection{Program take-up}

At the beginning of each meeting, the principal asked the families to fill in a presence sheet. Based on that information, Table 1 presents attendance of four groups of families: selected students in treatment classes; selected students in control classes; non-selected students in treatment classes; non-selected students in control classes. Comfortingly, take-up is large only for the selected in treatment classes: about 52\% have attended one of the meetings and $21 \%$ attended both. In contrast, only a tiny fraction of other families attended. As the principals were required not to invite them, it seems that the protocol has been implemented.

Given that selected families are mainly from modest social background and did not initially volunteer to participate into this program, above $50 \%$ take-up rate is rather high. In a similar school involvement experiment targeted only at volunteer families, Avvisati et al. 
(2013) obtain a similar participation rate in a comparable social environment. This high takeup rate suggests that the principals have made genuine effort to convince families to attend.

\section{Data}

We have first collected a number of administrative data from the schools as well as from the district. Data from the schools include a census of students at the start of the academic year 2010-2011 which provides us with baseline demographic and social characteristics. For each student and each term of the academic year 2010-2011, these data also include information on truancy, disciplinary sanctions (taken at any time by an ad hoc commission) as well as the average marks given by teachers in all topics (Maths, French, Physics, etc...). These marks are particularly important in our context because the score that determines the chances to obtain one's preferred choices in the centralized allocation system is based on the average marks received during the year. In addition, we have information on behaviour based on collective decisions that are taken by the pedagogical team at the end of each term, such as official warnings that work effort is too low. For all these outcomes, attrition is small (between 5\% and 8\%) and balanced across treated arms (see Appendix Table A1). It mostly reflects that some children change school during the academic year.

We also know attendance and marks received at the end-of-year national exam that is taken by ninth grade students (Diplôme National du Brevet). This exam takes places on the last day of the academic year; it is not compulsory and does not determine allocation to tracks. Some students are not present on the exam day, in spite of the fact that this is very often the occasion students are also informed on their track allocation. As will appear, absence is much higher for future dropouts. Therefore, information on absence on exam days provides us with an early signal of dropout likelihood. 
We then have exhaustive administrative data from the district which provide information on the application and allocation process, for each student in our sample. This includes:

(a) Application to the four preferred choices at the end of the treatment year. For each choice, we know the choice rank and the corresponding type of school and program. We also know if the student appealed or asked for repetition, unless she was admitted to the 3-year academic program.

(b) Students' actual situation one year after the treatment year (2011-212), as well as two years after the treatment year (2012-2013). As each student has a national identification number, we are able to track each one of them every year, in the national administrative bases. In particular, we know who is still present in a school or in an apprenticeship centre at any date; dropouts are the complement of this group. They represent $12 \%$ of our students after two years and $20 \%$ in our pre-selected group.

Data on students' applications and subsequent allocation (as well as on end-of-the-year examination) are directly obtained from the district and do not suffer from attrition.

Finally, we have run a series of surveys. In June 2011, parents were asked to fill in a questionnaire sent for us by the schools. Early July, in order to increase the response rate, we called non-respondent parents of selected students, and asked them the exact same set of questions. Overall, the response rate for the selected students' families is $75 \%$, balanced in the treatment and control groups (Appendix Table A1). Also we have checked that observed baseline characteristics are similar in both groups among the respondents.

We asked parents questions on their involvement in track choice. Questions measure how parents reach out for information with school personnel (attending general meetings, meeting teachers or career counsellors) and how satisfied they are with that information. Other questions relate to information sharing with other parents (attending parental 
organization meetings, talking with other parents about tracking). A last question measures their educational expectations for their child, specifically the highest secondary education diploma they expect he will obtain.

In order to measure friendship networks, we asked sports teachers to fill in a table reporting, for each student in the class, up to five best friends within that same class. Those teachers spend three hours per week with the students and are in a position to observe social relations much better than do other teachers. We run that survey during the first trimester and once again at the end of the school year. The response rate for the first survey is about $92 \%$ and similar across treatment arms (Appendix Table A1). At the end of the academic year, questionnaires were sent late and we were able to collect responses for only about half of the initial sample. We checked, however, that the sample with network information available both at the start and at the end of the year is balanced in treatment and control groups (Appendix Table A1). We also checked that baseline characteristics are similar in both groups among the respondents.

\section{Outcomes at the end of treatment year}

\subsection{Parental involvement and expectations}

The first basic objective of the program was to increase parents' involvement at school, improve their information about the education system and help them forming more realistic educational expectations for their children. The survey conducted at the end of the treatment year (June 2011) suggests that the intervention was successful in meeting these goals (Table 2). In particular, the survey reveals a strong positive effect on parents' involvement at school, with a 24 percent points increase in the proportion of selected parents who participated in information meetings at school. This is the most direct effect of the intervention and it shows that treated families did not simply substitute participation in the program for participation in 
regular information meetings at school. We also observe a significant impact on the proportion of selected parents who participated in meetings organized by parental organizations (+3.5 percentage points) as well as in the proportion of selected parents who report interactions with other parents (+9.3 percentage points). Overall, the intervention increases significantly the proportion of selected parents who are satisfied with the information received from the school (+5.6 percentage points).

Selected parents tend to be more involved and better informed in test classes, but they also tend to form more realistic expectations for their children. In particular, the intervention reduced the proportion of parents expecting that their child will complete a 3-year academic or vocational program, and therefore obtain the Baccalauréat, by about 8 percentage points, with $69 \%$ in treatment classes versus $77 \%$ in control classes. By construction, the vast majority of selected students have low or very low academic records and a very small minority only can be expected to complete a 3-year program ${ }^{9}$. Such overconfidence is not an isolated situation and it has been recently documented in the US College context (Jacob and Wilder, 2011, Stinebrickner and Stinebrickner, 2013). In our context, a proportion of 69\% expecting to complete a 3-year program in treatment classes remains unrealistic, but obviously less so than the $77 \%$ observed in control classes. The intervention does not entail more pessimistic expectations (very few parents expect that their children will dropout from high-school in both treated and control classes), but more modest ones (+3.4 percentage points increase in the proportion expecting a 2-year vocational degree) as well as more uncertain ones ( +5.4 percentage points say that they do not know yet what to expect).

\footnotetext{
${ }^{9}$ According to the longitudinal administrative database constructed by Ly and Riegert (2013), the probability of completing a 3-year program is about $8.2 \%$ nationally for those who fail to pass the national examination at the end of middle-school (average marks below 10/20) and 30\% for those who pass it without any honours (average marks between 10/20 and 12/20). Given that the vast majority of selected students either fail to pass this exam (58\%) or pass it without any honours (40\%), we can expect that only a small minority will complete a 3-year program. Furthermore, based on the control group in our data, we can observe that, two years after the intervention, the proportion of selected students still present in a 3-year program is only about $68 \%$ (and only about $49 \%$ succeeded to complete the first year of it). Hence, two years after the intervention, the upper bound for selected students' actual graduation rate in the control group is already about 9 percentage points lower than their parent's expected graduation rates at the end of the treatment year (77\%).
} 


\subsection{Performance and behaviour at the end of the treatment year}

The program was not designed to help pupils improve their performance at school. It is nonetheless possible that it entailed an improvement in school performance if only because it contributed to a better understanding of the role of the academic record in the track assignment process.

To test this assumption, Table 3 shows the effect of the intervention on marks obtained during the third term of the treatment year (i.e., the post-treatment term) as well as on average marks obtained during the treatment year, and specifically the annual average marks used by the assignment software to rank pupils’ applications. We do not find any significant effect on either outcome. This is an important result: any effect of the program on track choices can be interpreted as resulting from how tracks are perceived by students and parents, not as an indirect effect of improved marks on students' choice set. Furthermore, we do not find any significant effect on behaviour, as measured by truancy or official sanctions. We only detect a marginally significant improvement in work effort at the end of the treatment year, with a reduction in the number of official warnings given by the pedagogical team for lack of work in treated classes.

Finally, we have information on whether students register for the national examination which took place at the end of middle school, whether registered students were actually present or absent on the examination day and whether they passed the exam or not. As discussed above, this exam is not compulsory and the results are not taken into account in the track assignment process (nor at any other subsequent point of the school career). In fact, the results of the assignment process are sent to schools a few days before the examination day. Most schools take advantage of the fact that the vast majority of students actually come back to school on that day to provide them with the official results of the centralized assignment 
process, after the last test. In such a context, it is likely that students who are absent on examination day are not interested by their future assignment anymore, and are potential dropouts. As a matter of fact, in the control group, a student's absence on examination day is

very strongly correlated with subsequent dropout decision: the probability of high-school dropout is about 30 percent points larger for selected students who are absent than for students who are present. Overall, this absence is interpretable as a leading indicator of subsequent dropout decisions.

Under this assumption, the key question becomes whether the intervention has any effects on children's absence on that day. As it turns out, Table 3 does not show any effect of the treatment on registration rates, but reveals that the proportion of selected students who were absent on examination day is significantly lower in treated than in control classes (5.2\% versus $10.6 \%$ ). Also, the table shows that increased presence on examination day in treatment classes is not accompanied by any increase in the overall pass rates, which suggest that increased presence rate in treated classes is driven by very low achieving students only.

These results suggest that the treatment induced a significant number of very lowachieving pupils to come back to school on examination day, even though the likelihood of their passing the examination was very low. The simplest interpretation is that these students did not want to go on holidays without knowing whether (and where) they were assigned by the educational system. It is a first indication that the program succeeded in convincing them to stay in the school system at least for one additional year.

\subsection{Track choices}

The treatment has only very weak effects on pupils' academic record. The principal's intervention may nonetheless have a significant impact on the way students and their families perceive the value of different school options at the end of middle school and, consequently, 
on the tracks to which they choose to apply. Table 4 compares the choices made by selected students in treatment and control classes at the end of the treatment year.

The table first confirms that there is no significant effect of the program on the proportion of students applying for a 3-year academic program (about 17\%). This finding is consistent with the fact that the program has negligible effect on academic outcomes and, consequently, negligible effect on the proportion of students allowed to pursue in the more academic track by the pedagogical team.

By contrast, the table reveals a very significant impact of the intervention on the choices made by selected students who are not allowed to enter into a 3-year academic program. Invitation to the program induces an increase in the proportion of selected students who include 2-year vocational programs in their list of applications (+4.9 percentage points, which correspond to a $30 \%$ increase in this proportion) and a symmetrical decline in the proportion who either focus on a 3-year vocational program only or ask for grade repetition (-5.5 percentage points). We observe a decline in the proportion of selected students who apply only for 3-year vocational programs (-2.5 points) as well as in the proportion who ask for grade repetition or appeal (-3.0 points).

As 2-year programs are less selective than 3 -year ones ${ }^{10}$, treated students may have strategically set 2-year programs somewhere in their list only to avoid having all their applications rejected. Table 4 suggests that the effect of the intervention is deeper than that. Indeed, the increased proportion of lists that include 2-year programs is driven mostly by students who ask for a 2-year program as their first choice (+ 3.8 percentage points, a 34\% increase). The intervention changed students' beliefs about the option that fits best with their aspirations and academic record, not just they their understanding of strategic behaviour.

\footnotetext{
${ }^{10}$ In the control group, the difference in average marks between students whose first choice is a 3-year vocational program and those whose first choice is a 2-year vocational program represents about half a standard deviation (i.e., 9.0/20 versus 8.1/20).
} 
The vast majority of low-achieving students who are not allowed to enter into an academic track do not want to consider 2-year vocational programs as possible alternative options, although they are the least selective and, on average, the least difficult to access. These students prefer asking for grade repetition (with the hope of improving their chances for more ambitious options next year); or appeal (with the hope of forcing the decision for academic high school); or, at least, apply for 3-year vocational programs only. Our findings suggest that school principals convinced a significant fraction of these low-achieving students to scale down their ambitions and include 2-year programs in their choice list as a possible high-school assignment. Whether or not this strategy turns out to be successful remains an open question, however.

\section{Assignment outcomes}

\subsection{Outcomes one year after the intervention}

The program has significant effects on students' applications at the end of the treatment year, but it does not necessarily follow that it has an effect on students' assignment for the next academic year. If students induced to modify their applications all belong to the subset of students who intend in fact to get into apprenticeship (or to dropout), the subsequent effect on assignment is likely to be small. Similarly, if students convinced by school heads to apply for vocational programs fail to get admitted into these tracks, they may finally end up having to choose among the same second-best options as if they had not been treated (typically, repetition or dropout). In this scenario, the impact of the intervention on final assignments would again be much weaker than on initial applications.

To explore these issues, Table 5 focuses on selected students and shows the effect of the intervention on their actual assignment one year after the treatment. Consistent with our previous results, we do not observe any significant difference across treatment and control 
classes in the proportion of selected students enrolled into a 3-year academic program, but very significant differences in the distribution of assignments among those students who are not allowed to enter into an academic track. These differences are perceptible both within and outside the school system.

Within the school system, the intervention is followed by a significant increase in actual enrolment into 2-year high-school programs (+3.3 percentage points, almost doubling the proportion) and a symmetrical decrease in the share who actually repeat ninth grade (-3.5 percentage points, a decrease of about 28\%). The increase in enrolment into 2-year programs is driven mostly by students who put this type of track in their initial choice list. By contrast, the decline in grade repetition is driven mostly by students who did not put this specific option in their choice list: the program induced a 2.5 percent points decline in these "secondround” grade repetitions. By convincing students to broaden their choice lists so as to include less selective 2-year programs, school principals succeeded to increase the proportion who get enrolled into high-school tracks corresponding to their initial choices and thus decrease the proportion who end-up repeating.

The intervention also affected very significantly the assignments of students who chose to leave the school system. Specifically, it induced a significant increase in the proportion of students who get into apprenticeship and a parallel decrease in the proportion of students who drop out from education and training. One year after the treatment, we observe a 3.7 percentage points decline in the proportion of dropouts in the test group, which correspond to $43 \%$ reduction in this proportion.

As discussed above, apprenticeship does not belong to the set of options that students are asked to rank at the end of ninth grade. Hence, strictly speaking, it is not possible to determine whether the rise in enrolment into apprenticeship one year after the treatment corresponds to initial choices. However, it is unlikely to be a reaction to the first-round 
outcome of the assignment procedure. Getting enrolled into a training centre is a long and difficult process and it is very unlikely that the observed increase in enrolment may have been driven by decisions made mid-July (after the first-round of the assignment process). As it turns out, would-be apprentices not only have to find a seat in an adequate training centre (i.e., one that provides the qualification they want to get), but they also have to find a tutoring firm in the relevant industry and get hired by this firm as an apprentice. ${ }^{11}$ After a prospection period during which they send CVs and motivations letters to potential tutors, students get hiring interviews in April or May. Many of them start working for their tutors in July, before the start of the formal training period. In such a context, school principals can boost successful applications for apprenticeship centres only by leading students to produce a significant investment of time and effort long before the end of the academic year and the start of the assignment process.

Overall, the treatment provoked significant changes in the distribution of assignment both within the school system (more vocational high-school, less grade repetition) and outside the school system (more apprenticeship, less dropout). One simple interpretation for these shifts is that they correspond to two different processes, one affecting students intending to pursue secondary education and the other one affecting students intending to leave education. For the first group, principals convinced students and their families that they should not expect repetition or appeal to lead to better outcomes than 2-year vocational education; and that 3-year vocational programs would be more difficult to obtain than they thought. As a result of more realistic expectations, these students obtain one of their listed choices more often and end-up repeating less. As shown in the next section, this in turn generates lower dropout in the longer run. For the second group, which is also the group with the lowest

\footnotetext{
${ }^{11}$ Apprentices and their tutoring firms have to sign a specific 2-year or 3-year labour contract. They receive wages that are fixed by labour laws. These wages vary between $25 \%$ and $50 \%$ of the national minimum wage during the first year of training (depending on exact age of apprentices) and between $50 \%$ and $75 \%$ of the minimum wages during the last year of training.
} 
academic level ${ }^{12}$, the principals convinced students and families that apprenticeship is a much better way to get a foothold in the workplace than direct entry into the labour market. Furthermore, it represents a way to get additional education which is very different from formal schooling and likely to fit better with their aspirations. Schools traditionally tend to promote choices within the education system at the detriment of apprenticeship, and it is likely that the image of apprenticeship among teenagers suffers from this situation. There is thus a significant margin of action for principals to alter that perception.

If this interpretation of the two mechanisms is correct, it implies that the treatment did not induce any potential stayers to leave the school system, and vice versa. This has testable implications: the treatment must have no effect either on the proportion of students who chose to stay in the school system or on their pre-treatment characteristics. ${ }^{13}$ Any change in size or composition of the group of stayers induced by the treatment involves necessarily something more complex than simple shifts within each group. Appendix Table A2 shows that these conditions hold true. The proportion of students who chose to stay in the school system is very similar across treatment arms (about 85\%) and so are their pre-treatment characteristics. This finding is consistent with the assumption that school heads simply induced potential repeaters to elicit vocational high-school, and potential dropouts to go into apprenticeship.

\footnotetext{
${ }^{12}$ As a matter of fact, students in this second group (outside the school system) belong to the lower end of our selected students: in the control group, average mark is 7.2/20 instead of 8.9/20 for the first group ( $80 \%$ of a S.D. difference) and the share of former repeaters is $78 \%$ instead of $50 \%$. It is likely that the principals had a different approach to their situation.

${ }^{13}$ Equivalently, the treatment must have no effect either on the proportion or on the pre-treatment characteristics of students who chose to leave the school system. Note that other interpretations of our empirical results are possible. For instance, they would also come up if the program involved (a) a rise in the value of staying in the school system specifically for those who, in the counterfactual, would have remained outside and would have preferred dropout to apprenticeship; (b) a rise in the value of apprenticeship specifically for those who, in the counterfactual, would have remained inside the school system and would have preferred grade repetition to a two-year program.
} 


\subsection{Outcomes two years after the intervention}

One of the major effects of the intervention is to induce a fraction of selected students not to repeat ninth grade. It may be however that these students would have benefited from an additional year in middle school. Symmetrically, the program induced a fraction of students to get into apprenticeship (rather than to drop out), but these students may be disappointed by this choice, and dropout may only have been delayed. More in general, it could be that school principals contributed to distort students' perceptions in favour of choices that were maybe more realistic in the short run, but did not really fit with their specific aspirations or potential.

The most direct way to test this assumption is to compare grade advancement between test and control students two years after the treatment. If the intervention contributed simply to delay repetitions and dropout decisions, we should observe much weaker differences in grade advancement and dropout rates two years after treatment than one year after the treatment. Table 6 reveals that it is not the case.

Two years after the treatment, the gap in the proportion of students who succeed in completing the first year of their high school program, and moved to the second year, is not smaller than the initial gap in access to high-school programs across treatment and control groups ( +4.4 versus +4.1 percentage points). This is mostly driven by presence in the second year of a 2-year vocational program, which is very similar to the difference in assignment to the first year of a 2-year vocational program as observed initially $(+3.4$ vs. +3.3 percentage points). It is suggestive that those who were induced to get into this specific track (rather than to repeat) did not experience subsequently higher repetition (nor dropout) rates in high school.

A second important finding is that the difference in dropout rate across treatment and control students becomes even larger than one year after the treatment (-5.1 vs. -3.7 percentage points). The intervention does not only reduce the proportion of students who drop out just after the treatment year: we also observe a significant reduction in the proportion of 
students who dropout after repeating ninth grade (-1.5 percentage points), which accounts for the impact increase at the two years horizon.

Overall, the intervention contributed to reducing dropout through two different channels. First, it helped already disengaged middle school students to define new prospects outside the school system. Specifically, it induced a fraction of would-be dropouts to opt for apprenticeship just after the treatment year and most of them turned out to be able to complete the first year of their training program. This generated a gap in early dropout rates between treatment and control groups which persists over time. Second, the intervention helped lowachieving students still willing to pursue education to focus on more realistic prospects. In particular, it induced a fraction of would-be grade repeaters to enter into a 2-year vocational high-school program and, again, most of them turned out to be able to complete successfully the first year of their high-school program whereas an important fraction would likely have dropped out from school at the end of their second ninth grade, had they not been treated. This is a longer term mechanism through which school principals helped to reduce dropout rates.

To further explore the mechanism driving this latter result, we have also analyzed the impact of the intervention on students' academic record at the point in time when they leave middle school. Specifically, we have considered academic outcomes observed at the end of the last ninth grade: outcomes are thus measured at the end of the treatment year for those who did not repeat and one year later for those who repeated. Assuming that the intervention has no direct effect on academic performance (as suggested by Table 3), difference in marks at the end of the last ninth grade across treatment and control groups identify the effect of not repeating ninth grade on those induced by the treatment not to repeat. As it happens, Appendix Table A3 suggests that this effect is not significant. Consistent with no effects on marks through repetition, the program has no significant effect neither on the proportion of students who get into an academic track nor on the proportion who get into a 3-year 
vocational track. These findings are suggestive that a fraction of grade repetitions at the end of middle school have no impact on students' academic record at entry into high school, which is consistent with earlier findings, obtained in different institutional contexts (Jacob and Lefgren 2009, Manacorda, 2012).

The table also reveals that the gap in dropout rates between test and control students tends to be larger at the end of the second ninth grade than after the treatment year. In fact, the gap in dropout rates observed at the end of the last ninth grade is almost as large as the gap observed two years after the treatment ( -4.8 vs. -5.1 percentage points). Hence, most of the increase in this gap between year 1 and year 2 seems to be driven by the fact that a large fraction of students induced not to repeat ninth grade at the end of year 1 would have dropped out from school just after the end of their second ninth grade, had they not been treated.

\section{The role of friendship networks}

Peer pressure has long been identified as a potential determinant of pupils’ perceptions and choices ${ }^{14}$. It is nonetheless very difficult to provide robust evidence on whether peers really exert a causal influence on pupils' decisions. Progress in this direction has been limited by the difficulty of observing independent variation in the influence exerted by ones' peers, as pupils within the same class are in general subject to similar influences. In this section we exploit the "partial population" design of our experiment to overcome this issue and to provide estimates on how independent changes in aspirations of selected classmates affect non-selected pupils. Building on our surveys on friendship networks, we also explore the

\footnotetext{
${ }^{14}$ For recent contributions to the large literature on peer group influence on students' behaviour, see e.g. Avvisati et al. (2013), Card and Giuliano (2013), Kremer and Levy (2008). Recent research in cognitive science is also suggestive that the brain regions that are involved in taking into account the long term consequences of behaviors as well as peers' opinion develop most rapidly during adolescence (Mc Clure et al. 2004, Blakemore, 2008).
} 
extent to which the intervention is followed by an evolution of social interactions among pupils within treated classes. $^{15}$

\subsection{Spillover effects on non-selected pupils}

The two first columns of Table 7 focus on the full sample of non-selected students and provide estimates of the indirect effects of the intervention on their average marks and applications at the end of the treatment year. Specifically, for each possible track choice, we show the impact of being in a treatment class on the probability of including this choice in the list of applications. We do not find any significant effect either on average marks or on choices.

One possible reason why we do not detect spillover effects on non-selected students is because students do not in general interact with all their classmates, but mostly with a subset of friends. According to our baseline friendship network survey, an important fraction of nonselected students (about 60\%) have no friends among selected ones: the absence of spillover effects on non-selected students thus comes as no surprise.

To further explore this assumption, columns 4-6 of Table 7 provide a separate analysis of spillover effects on the subgroup of non-selected students who have at least one friend among their selected classmates, as measured in the baseline survey. We still find no spillover effects on marks, but we are now able to detect some spillover effects on applications, although not significant at standard levels. Another reason why spillover effects on nonselected students may be relatively weak is that the majority of non-selected students have a good academic level and are not at risk of being denied the academic track. For a large fraction of non-selected students, there is in fact little room for peers to have any influence on their choices. To address this issue, the last three columns of Table 7 further focuses on the

\footnotetext{
${ }^{15}$ Some descriptive statistics on friendship ties are given in Appendix table A4. Consistent with a long standing literature on friendship networks, we find that pupils are very similar to their friends in terms of gender or academic status (see e.g., Shrum et al., 1988, Tuma and Hallinan, 1979).
} 
about 20\% non-selected pupils, among those with some selected friends, whose academic level is relatively low compared to other non-selected pupils (those whose average marks during pre-treatment term is $12 / 20$ or below). These mid-ability pupils are those for which the question of choosing between a general and a vocational track is most likely to remain open until the very end of the year. ${ }^{16}$ Comfortingly, when we replicate our analysis on this subset of non-selected pupils, we detect significant negative effect on the proportion of students applying for an academic track (-7.7 percentage points) and a parallel positive shift on the proportion applying for a vocational track (+8.7 percentage points). These results are clearly suggestive that pupils’ choices may be influenced by their friends, especially when they have a similar academic level and when they are facing similar education alternatives. ${ }^{17}$

Table 8, upper panel, demonstrates that these spillovers on choices translate into similar significant spillovers on assignment one year after the treatment. When we focus on the group of non-selected students with both selected friends and relatively low marks, we observe that they have been induced to get into a vocational track rather than into an academic track by about 9.2 percentage points. When we replicate the same analysis two years after the treatment, these spillover effects tend nonetheless to fade out (Table 8, lower panel). At this point in time, the intervention is still associated with a higher proportion of non-selected students in vocational tracks, but this effect is about $30 \%$ lower than one year after the treatment $(+7.0$ percentage points versus +9.2 percentage points $)$ and not significant at standard levels anymore. This finding suggests that a fraction of the students who have been induced by their selected friends to get into a vocational track rather than an academic one at

\footnotetext{
${ }^{16}$ Within this sub-group, the proportion of pupils who pursue into the general track is actually only about $39 \%$ (in the control group), i.e., not larger than the proportion who pursue into a vocational track. By contrast, within the subgroup whose average marks is above 12/20 during the first term, the proportion who pursue into the general track is about $95 \%$.

${ }^{17}$ Notice that if there are significant friendship ties across classes so that non-selected students in control classes are influenced by selected students in treatment classes, this would tend to bias our spillover estimates towards zero.
} 
the end of middle school, would have got into this type of track anyway before the end of high school, had they not been treated.

Spillover effects on non-selected students' choices may be driven by treated students being able to pass on information received from the principal to their non-selected friends. Alternatively, these effects may be driven by the desire of non-selected students attend the same schools as their selected friends. ${ }^{18}$ It is typically very difficult to provide robust evidence on the channels through which eligible individuals affect their non-eligible peers. However, using schools' identification number, we have checked that the treatment has no effect on the probability that non-selected students apply for (or enter) the same schools as one of their friends, even when we focus on the $20 \%$ non-selected students with selected friends and relatively low marks. This result is suggestive that spillovers on non-selected students are not driven by the sole desire to get into the same school as their friends, but reflect a deeper influence. ${ }^{19}$

\subsection{Effects on networks' evolution}

The program generated significant spillover effects on non-selected students whose academic level was immediately above those of selected ones. Given this fact, it is likely that the program also generated spillover effects within the group of selected students. Selected students being exposed to more irreversible decisions than non-selected ones (such as the decision to dropout), it is even likely that these spillover effects have been more persistent than those on non-selected students. Unfortunately, spillover effects on eligible individuals

\footnotetext{
${ }^{18}$ Vocational and academic education programmes typically take place in different high schools. Hence, pupils who want to attend the same establishment as their friends who opt for a vocational track generally have to enter a vocational track too, if not of the same kind.

${ }^{19}$ Following the argument in Bramoullé et al. (2009), we have also checked that having friends with selected friends has, as such, no significant effect on non-selected pupils' choices, even though it affects the proportion of friends choosing vocational education. Again, this result is suggestive that it is not so much friends' behaviour that matters as their exposition to the intervention via their treated friends.
} 
cannot be robustly identified in a set-up like ours, where there is no random variation in the proportion of eligible individuals across experiment units (Baird et al., 2012). ${ }^{20}$

Building on our longitudinal information on friendship ties, we are nonetheless able to explore whether the intervention induced selected students to have more or less interactions with specific classmates during the treatment year. As recently emphasised by Carrell et al. (2013), the impact of public policy interventions on network structure may be a channel through which interventions affect behaviours. Recent research also emphasises that network stability may be, as such, a source of improvement in school outcomes (Lavy and Sand, 2012). Reduced dropout rates in test classes could also be in part the consequence of more stable friendship networks and increased school integration of selected students in these classes.

To explore these issues, Table 9 focuses on the sample of selected students for which we observe friendship networks both pre and post treatment ${ }^{21}$ and compares the evolution of networks' size and composition in test and control classes over the treatment year. The table first reveals that the intervention actually improved network stability. Specifically, classmates who are nominated as friends both at the beginning and at the end of the treatment year represent a proportion of the overall set of nominated friends which is significantly higher in treated classes (51.4\%) than in control classes (41.0\%). This increased proportion of persistent friends reflects a significant reduction of both the proportion of initial friends who are lost (-12.4 percentage points) and the proportion of new friends who are gained over the school year (-6.8 percentage points). Also, we observe a significant increase in the proportion

\footnotetext{
${ }^{20}$ We have checked that the impact of the intervention on selected students' propensity to dropout is significantly stronger for those who have some selected friends than for those who have non-selected friends only. This result is clearly consistent with the existence of spillover effects across selected classmates, but it may also reflect that the same unobserved factors contribute to explaining both selected students' propensity to have selected friends and students' responsiveness to the intervention.

${ }^{21} \mathrm{As}$ discussed above, the sample in this analysis is constrained by the about $45 \%$ response rate in the endline network survey. Appendix Table A1 provides evidence that the selection in the sample used for Table 9 is ignorable: the treatment has no effect on the probability of being selected in this sample. Further, we checked that the estimated direct effects of the treatment on students' behaviours are similar in this specific sample as in the full sample of selected students.
} 
of selected friends that turn out to be persistent friends (+6.2 percent points, a $44 \%$ increase in this proportion), suggesting that the meetings contributed not only to adjust aspirations, but also to strengthen initial friendship ties across participants.

Table 9 also reveals that this higher stability of networks in test classes is accompanied by a reduced variance in the number of friends, with a lower proportion of students with either 0 friend or 4-5 friends and a higher proportion of students with 1-3 friends. At the end of the treatment year, the average size of networks is about the same in treatment classes as in control classes (about 2.7 friends on average), but networks are more often composed of a core group of 1-3 persistent friends in treatment classes. When we replicate this analysis on the network of friends nominated before treatment, we do not find any difference on the distribution of the number of friends, as implied by randomization: the tightening of networks in test classes is clearly a consequence of the intervention.

Finally, Table 9 confirms that the intervention contributed to significant changes in the composition of friendship networks at the end of the treatment year. In particular, it reveals a significantly lower proportion of future dropouts/grade repeaters among end-of-the-year friends (-5.4\%) as well as a significantly higher proportion of future 3-year program students $(+7.8 \%)$. On the one hand, these impacts reflect that many selected students have friends who are themselves selected and who are themselves induced by the intervention to modify their track choices after middle-school. But on the other hand, they may also reflect that selected students do not gain (or loose) the same type of friends during the school year in test and control classes.

To separate the two mechanisms, Table 9 also reports the differences in future track choices and treatment status of friends nominated by selected students at the beginning of the school year. They represent the effects that would have been observed on end-of-the-year friends in the absence of networks' changes over the school year. The table reveals that these 
effects are, for the most part, very similar to the actual effects observed on end-of-the-year friends. For example, the impact of the intervention on the proportion of future dropout friends is almost as significant on beginning-of-the-year friends (-4.2\%) as on end-of-the-year friends (-5.3\%). Thus, the effect of the intervention on the type of friends with whom selected students interact at the end of the year seems to reflect for the most part the effects of the intervention on early friends themselves. There is nonetheless one important exception: the impact of the intervention on the proportion of late friends who are going to get into a 3-year program is stronger than the impact on the proportion of early friends who are going to get into a 3-year program $(+7.8 \%$ versus $+2.2 \%)$, the later being non statistically significant at standard level. In fact, selected students in control classes tend to lose those high performing friends over the year (from $77.6 \%$ to $69.6 \%$ ), but such a change is almost negligible among treatment students (from $79.8 \%$ to $77.4 \%$ ), which is compatible with the notion that treated networks are more stable (although, strictly speaking, the difference between the two changes is only marginally significant). Given that the intervention has no direct effect on access to 3year programs, the increase in the proportion of end-of-the-year friends assigned to a 3-year program can only be driven by a specific evolution of networks in test classes, and namely by a specific strengthening of friendship ties between students who are "at risk" of dropping out and their high achieving classmates.

Overall, by adjusting and harmonizing aspirations, school head's intervention seems to protect social ties from both disruption and dispersion. It also contributes to increase interactions between students who are at-risk of dropping out and students who are going to get into selective high-school program. Given previous evidence on spillovers, it is likely that those students influence each other and maintain their friendship ties as their aspirations converge. One channel through which school head's intervention may have may have been amplified is by strengthening and improving the quality of social ties. 


\section{Further estimates: the causal effect of aspirations on dropout behavior}

There is a long standing and ongoing debate in social sciences on the role of aspirations in models of educational attainment. It has often been emphasised that high-ability students from low income families often lack ambitions, which may explain why they often do so poorly at school and on the labour market (see e.g. Sewell et al., 1969, Hanson, 1994, Alexander et al. 1994, Morgan and Mehta, 2004, Hoxby and Avery, 2012). On the other hand, the psychological literature has long suggested that aspirations that are not tempered by a realistic understanding of obstacles and opportunities may be associated with very poor outcomes too (Gottfredson, 1981, Higgins, 1987, Heckhausen and Tomasik, 2002, Reynolds and Baird, 2010).

The causal effect of aspirations (what students hope to do) on subsequent educational achievement is hard to evaluate because both aspirations and achievements are typically affected by similar circumstances. In particular, they are both related to children's early school achievement and parental background. By generating adjustments in aspirations that are independent from children's aptitude and background, our intervention provides a tool to overcome this issue. While the previous sections have highlighted the reduced-form effects of the treatment on students' aspirations and outcomes, this section uses the treatment as an instrument to identify the causal effect of aspirations on outcomes. Specifically, we focus on selected students who were identified as at risk of dropping out from education (the selected ones), and evaluate the extent to which their being induced to adopt more realistic aspirations is followed by a reduction in their dropout rates.

With respect to the exact channels through which changes in aspirations affect subsequent outcomes, we cannot separately identify direct and spillover effects at the student level, since there is no random variation in the proportion of eligible peers across classes or 
friendship networks. The exclusion restriction would thus not hold at the individual level. Given this, we define outcomes at the aggregate (class) level and thus provide estimates of the impact of average class aspirations on average class dropout behaviour. These class-level effects encompass both direct and spillover effects. Specifically we assume the following class level model:

$$
Y_{\mathrm{c}}=\theta A_{\mathrm{c}}+\delta X_{\mathrm{c}}+\varepsilon_{\mathrm{c}}
$$

where $Y_{\mathrm{c}}$ represents the average educational outcome of selected students in class c, $A_{\mathrm{c}}$ represents the average level of aspiration of selected students in class c, $X_{\mathrm{c}}$ is an average of baseline control variables, and $\varepsilon_{\mathrm{c}}$ unobserved random characteristics. In this model, assuming that treatment status $T_{\mathrm{C}}$ is independent from both observed and unobserved characteristics $(X$ and $\varepsilon$ ), we can use $T_{\mathrm{c}}$ as an instrumental variable to provide robust identification of parameter $\theta$, the causal effect of adjusting selected students' average level of aspiration in a class on their subsequent average educational outcomes.

This class level model could be derived from a standard linear-in-means individuallevel model (Manski, 1993) where selected students interact in groups within classes and where individual outcomes are affected by own level of aspirations as well as by the average level of aspirations and average outcomes of selected peers. In this set-up, parameter $\theta$ represents the sum of direct and indirect effects of aspirations, inflated by the social multiplier.

Table 10 shows the results of this class-level regression analysis. In panel A, we use students' applications at the end of the treatment year as a measure of aspirations. This is both a subjective and a high-stakes measure. For the sake of simplicity, we define two basic levels of aspirations, where the highest level $\left(A_{c}=1\right)$ corresponds to students applying exclusively for 3-year programmes (or repetition) while the lowest level corresponds to those who accept to consider 2-year programmes as a possible option $\left(A_{c}=0\right)$. As discussed in previous sections, 
moving from $A_{\mathrm{c}}=1$ to $A_{\mathrm{c}}=0$ can be interpreted as moving from highly unrealistic aspirations to more realistic ones. Using this definition, the first column of Table 10 shows the first-stage effect of treatment status on the average level aspirations. It confirms that school principals' intervention contributes to significantly reducing the proportion of at risk students forming unrealistic aspirations within classes (-6.1 percentage points). The second column shows the reduced-form effect when we use the proportion of dropouts one year after the treatment as a measure of students' average outcomes $Y$. It shows that the intervention is followed by a significant decrease of about 3.5 percentage points in the proportion of early dropouts one year after the treatment. Consistent with the linear-in-means assumptions, we obtain very similar reduced-form estimates when we work at the class level as when we work at the student level. Due to the relatively small number of class-level observations, the corresponding IV estimate (0.58) is significant at the $13 \%$ level only. It is suggestive that a 10 percentage point's reduction in the proportion of at-risk students with unrealistic aspiration generates a 5.8 percentage points reduction in early dropout rate.

To test for the robustness of these results, we built on the questionnaire sent to parents. It provides us with an independent measure of parents' educational expectations, and namely the highest secondary diploma that parents think their child will obtain. ${ }^{22}$ We can define two basic levels of expectations, where the highest level corresponds to parents expecting that their children will complete a 3-year programme while the lowest level corresponds to those who either expect a 2-year diploma only or do not know what to expect. Interestingly, the share of parents with high expectations is similar with the share of students with high aspirations (a little below $80 \%$ in the control group). Panel B of Table 10 shows the results of replicating our regression analysis using parents' expectation as an independent variable

\footnotetext{
${ }^{22}$ The terms of expectations and aspirations are often used interchangeably, even though they do not refer to the same concept. Expectations correspond to what individuals think will occur, whereas aspirations correspond to what they hope. It is beyond the scope of this paper to provide separate identification of the effects of aspirations and expectations.
} 
instead of students' aspiration. Comfortingly, estimated first-stage and reduced-form effects are still significant at standard level ${ }^{23}$ and we end up with an evaluation of the causal effect of over-optimistic expectations which is qualitatively similar to the effect of unrealistic aspirations, suggesting that a 10 points reduction in the proportion of over-optimistic expectations, as such, is able to cause a 4.9 percentage points decline in the proportion of early dropouts.

This strong elasticity of dropout to aspirations may explain why a relatively simple and low cost program was able to affect dropout substantially. Low cost is a shared property of information interventions, but providing information is not always efficient. Experiments from Bettinger et al. (2012) and Hoxby and Turner (2013) show that providing information on aid or admission into college is efficient only if it comes altogether with direct help or administrative simplification. Downs et al. (2009) or Bertrand et al. (2010) illustrate the potential of manipulating or framing information. As mentioned earlier, facilitation by the school principal must have made this intervention particularly efficient.

By adjusting aspirations, an extension of the programme is likely to increase the overall proportion of low-achieving students who are willing to pursue in tracks that correspond to their actual academic abilities. Appendix B shows that the wage value of the intervention measured in intention-to-treat, like the rest of the estimates, is a wage increase by almost 3\% on selected students. Hence, an extension of the programme has the potential to reduce significantly overall dropout rates and increase future wages, provided that it is accompanied by a parallel increase in school supply. Given that potential dropouts would be induced to enter into vocational tracks that are at the bottom of the tracking scale, the extension of the program would not generate negative spillover effects on students who get access to the more selective tracks. The only costs of extending the programme would be the necessary

\footnotetext{
${ }^{23}$ In panel B, outcomes are measured on the subsample of respondents to the surveys on parents whereas in panel A they are measured on the full sample. It is the reason why estimated reduced-form effects are different across panel A and B.
} 
budgetary costs of adjusting school supply and creating new 2-year vocational positions in order to absorb the increased demand for education from potential dropouts.

\section{Conclusion}

Based on a randomized controlled trial, this paper documents aspects of schooling decisions and dropout behavior that have received limited attention. Largely irreversible qualitative choices have to be made at some point of most schooling systems, and we consider such a decisive tracking assignment taking place at the end of middle-school in France. We observe that low performing students in mostly deprived areas have inadequate expectations in face of a complex choice set and assignment system. Many overestimate their chances to end up in the academic system and fail to consider less selective programs as possible options. They either undervalue vocational education or overestimate their chances to end up in the academic system. This leaves room for intervention and we show that even a low intensive, costless treatment facilitated by the school principals can adjust those student's aspirations as well as their parents' expectations. Because expectations and aspirations are important determinants of school outcomes, this results in substantial effects in schooling status: dropout is reduced by $25 \%$ in this target population (from $20 \%$ to $15 \%$ ), in part through a decrease in ineffective grade repetition, at the benefit of vocational education.

Our rich information on friendship networks allows us to further show that acting on some individuals has complex implications for social interactions. We have evidence that the principals' intervention translated into different network equilibrium: treated students have more stable networks and in particular they keep ties more often with their better performing friends. In turn some of their friends are influenced in their track choices, and the two mechanisms probably foster each other. 
Overall, this experiment shows that it is possible to influence adolescent school choices in such a way likely to improve their lifelong outcomes at little direct cost. We interpret this in relation to two features: aspiration is a strong determinant of school outcomes, specifically dropout; and aspiration is malleable, the school principals being able to affect them significantly. Whereas the literature has long considered low aspirations of high performing low background students, this paper show that educational outcomes of low performing students can also be improved under the same approach.

\section{References}

Alexander K., Entwisle D. And Bedinger S. (1994), "When expectations work: Race and socioeconomic differences in school performance”, Social Psychology Quarterly, vol. 57, pp. 283-299.

Abriac D., Rathelot R. and Sanchez R. (2009), "L’apprentissage, entre formation et insertion professionnelle”, Insee Référénces, pp. 57-74.

Avvisati F., Gurgand, M., Guyon N. and Maurin E. (2013), “Getting Parents Involved: a Field Experiment in Deprived Schools”, forthcoming, Review of Economic Studies.

Avvisati F., Gurgand, M., Guyon N. and Maurin E. (2011), "Communication des collèges et implication des parents d'élèves”, Rapport pour le Fonds d'expérimentation pour la jeunesse.

Baird S., Bohren A., McIntosh C. and Ozler B. (2012), "Designing experiment to measure spillover effects and thresholds effects”, Unpublished Manuscript.

Banerjee A., Chandrasekhat A., Duflo E. and Jackson M. (2013), "The diffusion of microfinance”, Science, vol. 314, 1236498-1.

Belfield C. and Levin H. (2007), The price we pay: economic and social consequences of inadequate education, Washington, DC: The Brookings Institution.

Bertrand M., Karlan D., Mullainathan S., Shafir E. and Zinman J. (2010), "What’s advertising content worth? Evidence from a consumer credit marketing field experiment”, Quarterly Journal of Economics, vol. 125, pp. 263-305.

Bertrand, M. and Schoar A. (2003), "Managing with Style: The Effect of Managers on Firm Policies." Quarterly Journal of Economics, vol. 118, pp. 1169-1208.

Bramoullé Y., Djebbari H. and Fortin B. (2009), "Identification of peer effects through social networks”, Journal of Econometrics, vol. 150, pp. 41-55.

Bettinger E., Long B., Oreopoulos P. and Sanbonmatsu L. (2012), “The Role of Application Assistance and Information in College Decisions: Results from the H\&R Block FAFSA Experiment", Quarterly Journal of Economics, vol. 127, pp. 1205-1242.

Blakemore S.-J. (2008), “The Social brain in adolescence”, Nature Reviews Neuroscience, vol. 9, pp. 267-277. 
Branch G., Hanushek E. and Rivkin S. (2012), "Estimating the Effect of Leaders on Public Sector Productivity: The Case of School Principals”, NBER Working Paper 17803.

Card D. (2001) "Estimating the return to schooling: progress on some persistent econometric problems", Econometrica, vol. 69, pp. 1127-1160.

Card D. and Giuliano L. (2013), "Peer Effects and Multiple Equilibria in the Risky Behavior of Friends”, The Review of Economics and Statistics, vol. 95, pp 1130-1149.

Carrell S., Sacerdote B. and West J., (2013), "From natural variation to optimal policy? The importance of endogenous peer group formation”, Econometrica, vol. 81, pp. 855-882.

Dearden L., Emmerson C., Frayne C. and Meghir C. (2009) "Conditional Cash Transfers and School Dropout Rates”, Journal of Human Resources. vol. 44, pp. 827-857.

Downs J. Loewenstein G. and Wisdom J., 2009, "Strategies for promoting healthier food choices”, American Economic Review, 99(2), 159-64.

Dhuey E. and Smith J. (2013), "How Important Are School Principals in the Production of Student Achievement?”, mimeo.

Dynarski M., Clarke L., Cobb B., Finn J., Rumberger R. and Smink J. (2008), Dropout Prevention: A Practice Guide (NCEE 2008-4025). Washington, DC: National Center for Education Evaluation and Regional Assistance, Institute of Education Sciences, U.S. Department of Education.

Eckstein Z. and Wolpin K.I. (1999), "Why Youth Drop out of High School: The Impact of Preferences, Opportunities and Abilities”, Econometrica, vol. 67, pp. 1295-1339.

European Commission (2013), “The Structure of European Educational Systems 2012-2013: Schematic Diagrams”, Eurydice Highlights.

Gottfredson L. (1981), "Circumscription and compromise: a developmental theory of occupational aspirations”, Journal of Counseling Psychology, vol. 28, pp. 545-579.

Griffith J. (2001), "Principal leadership of parent involvement”, Journal of Educational Administration, vol. 39, pp. 162-186.

Hanson S. (1994), "Lost talent: unrealized educational aspirations and expectations among US youths”, Sociology of Education, vol. 67, pp. 159-183.

Heckman J.J. (2008), "Schools, Skills, and Synapses", Economic Inquiry, vol. 46, pp. 289324.

Heckhausen, J. and Tomasik, M. (2002). Get an apprenticeship before school is out: How German adolescents adjust vocational aspirations when getting close to a developmental deadline. Journal of Vocational Behavior, vol. 60, pp. 199-219.

Higgins E. (1987), "Self-discrepancy: a theory relating self and affect”, Psychology Review, vol. 94, pp. 319-340.

Hoxby C. and Avery C. (2012), "The missing ones-off: the hidden supply of high-achieving, low income students”, NBER Working Paper 18586.

Hoxby C. and Turner S. (2013), "Expanding college opportunities for high-achieving low income students”, SIEPR Discussion Paper no 12-014.

Jacob B. and Lefgren L. (2009), "The Effect of Grade Retention on High School Completion”, American Economic Journal: Applied Economics, vol. 1, n³, pp. 33-58. 
Jacob, B. and Wilder T. (2011), "Educational Expectations and Attainment”, in Whither Opportunity? Rising Inequality and the Uncertain Life Chances of Low-Income Children, edited by G. J. Duncan and R. J. Murnane, New York, NY: Russell Sage Press.

Jensen, R. (2010), “The (Perceived) Returns to Education and the Demand for Schooling”, Quarterly Journal of Economics, vol. 125, pp. 515-548.

Kremer M. and Levy D. (2008), "Peer Effects and Alcohol Use among College Students", Journal of Economic Perspectives, vol. 22, pp. 189-206.

Lavy V. And Sand E. (2012), “The Friends factor: how students' social networks affect their academic achievement and well-being?”, NBER Working Paper 18430.

Ly S.T. and Riegert A. (2013), "Persistent Classmates: How Familiarity with Peers Protects from Disruptive School Transitions”, Working paper 2013-21, Paris School of Economics.

Manacorda M. (2012), “The cost of grade retention”, Review of Economics and Statistics, vol. 94, pp. 596-606.

Manski C. (1993), "Identification of Endogenous Social Effects: The Reflection Problem”, The Review of Economic Studies, vol. 60, pp. 531-542.

Martinelli D. and Prost C. (2010), "Le domaine d'études est déterminant pour les débuts de carrière", Insee Première, No. 1313, octobre.

Maurin E. and Xenogiani T. (2007), "Demand for education and labor market outcomes: lessons from the abolition of compulsory conscription in France”, Journal of Human Resources, vol. 42, pp. 795-819.

Mc Clure S., Laibson D., Loewenstein G., and Cohen J. (2004), "Separate Neural Systems Value Immediate and Delayed Monetary Rewards”, Science, vol. 306, pp. 503-507.

Ministère de l'éducation nationale (2011), Géographie de l'école, no 10.

Morgan S. and Mehta J. (2004), "Beyond the laboratory: Evaluating the survey evidence for the disidentification explanation of Black-White differences in achievement", Sociology of Education, vol. 77, pp. 82-101.

Murnane R. (2013), “US High School graduation rates: patterns and explanations”, Journal of Economic Literature, vol. 60, pp. 370-422.

Nguyen T. (2008), "Information, Role Models and Perceived Return to Education: Experimental Evidence from Madagascar" unpublished manuscript.

OECD (2008), Education at a glance 2008: OECD Indicators, OCDE, Paris.

Oreopoulos P. (2006), "Estimating Average and Local Average Treatment Effects of Education when Compulsory Schooling Laws Really Matter," American Economic Review, vol. 96, pp. 152-175.

Oreopoulos P. (2007), "Do Dropouts Drop Out too soon? Wealth, health and happiness from compulsory schooling”, Journal of Public Economics, vol. 91, pp. 2213-2229.

Oreopoulos P., Lang D. and Angrist J. (2009), "Incentives and Services for College Achievement: Evidence from a Randomized Trial" American Economic Journal: Applied Economics, vol. 1, pp. 136-63.

Reynolds J. and Baird C. (2010), "Is there a downside to shooting for the stars? Unrealized educational expectations and symptoms of depression”, American Sociological Review, vol. 75, pp. 151-172. 
Roth A. E. (2008), "Deferred Acceptance Algorithms: History, Theory, Practice, and Open Questions”, International Journal of Game Theory, vol. 36, pp. 537-569.

Rumberger R. W. and Lim S. A. (2008), "Why students drop out of schools: a review of 25 years of research”, California Dropout Research Project, Report n¹5.

Sewell W. H., Haller A. O. and Portes A. (1969), "The Educational and Early Occupational Attainment Process”, American Sociological Review, vol. 34, pp. 82-92.

Shrum W., Cheek Jr. N., and Hunter MacD. S. (1988), "Friendship in School: Gender and Racial Homophily”, Sociology of Education, vol. 61, pp. 227-239.

Stinebrickner, T. R. and Stinebrickner R. (2013), “Academic Performance and College Dropout: Using Longitudinal Expectations Data to Estimate a Learning Model,” forthcoming, Journal of Labor Economics.

Tuma N. B. and Hallinan M.T. (1979), “The Effects of Sex, Race and Achievements on Schoolchildren’s Friendship”, Social Forces, vol. 57, pp. 1265-1285.

Walker I. and Pettigrew T. (1984), "Relative deprivation theory: an overview and conceptual critique”, British Journal of Social Psychology, vol. 23, pp. 301-310.

Wheaton B. (1994), "Sampling the stress universe", in Stress and mental health: contemporary issues and prospects for the future, edited by W. Avison and I. Gotlib, New York, Plenum Press, pp. 77-114. 
Table 1: Participation into the program (in \%)

\begin{tabular}{lcccccc}
\hline \hline & \multicolumn{2}{c}{ Selected students } & & \multicolumn{2}{c}{ Non-selected students } \\
\cline { 2 - 3 } \cline { 5 - 6 } & Test & Control & & Test & Control \\
\hline ... first meeting & 45,5 & 2,5 & & 1,3 & 0.1 \\
$\ldots$.. second meeting & 27.7 & 0.4 & & 1.3 & 0.0 \\
$\ldots$.. two meetings & 21.0 & 0.4 & & 0.7 & 0.0 \\
$\ldots$.. one or two meetings & 52.2 & 2.5 & & 1.9 & 0.1 \\
Number of observations & 600 & 510 & & 1662 & 1415 \\
\hline \hline
\end{tabular}

Note : The sample includes all students, except those from one school, that did not fill the presence sheets. 
Table 2: Treatment effects on parental involvement and expectations, selected students

\begin{tabular}{|c|c|c|c|c|}
\hline & $\mathrm{C}$ & $\mathrm{T}-\mathrm{C}$ & (se) & Obs. \\
\hline \multicolumn{5}{|l|}{ Information from school : } \\
\hline General information meetings & 16.0 & $+24.2 * *$ & 3.0 & 836 \\
\hline $\begin{array}{l}\text { Individual meetings with career } \\
\text { counsellor }\end{array}$ & 22.7 & +1.5 & 2.7 & 837 \\
\hline Individual meetings with teachers & 40.6 & +2.2 & 3.7 & 842 \\
\hline \multicolumn{5}{|l|}{ Interaction with other parents : } \\
\hline $\begin{array}{l}\text { Has attended meetings of parents' } \\
\text { organisation }\end{array}$ & 9.0 & $+3.5^{*}$ & 2.1 & 834 \\
\hline Has talked with other parents & 43.8 & $+9.3^{* *}$ & 3.2 & 831 \\
\hline \multicolumn{5}{|l|}{ Satisfaction : } \\
\hline Happy with school information & 53.3 & $+5.6^{*}$ & 3.1 & 835 \\
\hline \multicolumn{5}{|l|}{ Expected diploma : } \\
\hline Baccalauréat (3-year track) & 77.5 & $-8.2 * *$ & 2.8 & 830 \\
\hline Vocational certificate (2-year track) & 10.3 & $+3.4^{*}$ & 2.0 & 830 \\
\hline No diploma & 0.5 & $-0.6^{*}$ & 0.3 & 830 \\
\hline Do not know & 11.6 & $+5.4^{* *}$ & 2.2 & 830 \\
\hline
\end{tabular}

Note: Each row corresponds to a different model, based on parent's endline survey. Column (C) shows the average response of selected students' parents in the control group. Column (T-C) contains the coefficient of a treatment class dummy. We use a linear probability model where we control for school dummies, first trimester average marks, gender, currently repeating dummy, low income dummy, as well as dummies for missing first trimester, and missing repeater information. Column (se) shows corresponding standard error clustered at the class level. * significant effects at the $10 \%$ level; ** at the $5 \%$ level. 
Table 3: Treatment effects on behaviour in school and academic performance at the end of the treatment year, selected students

\begin{tabular}{lcccc}
\hline \hline & C & T-C & s.e. & Obs. \\
\hline • Academic performance & & & & \\
Average marks, term 3 (/20) & 8.44 & -0.00 & 0.11 & 1047 \\
Annual average marks (/200) & 86.5 & +0.7 & 0.9 & 1097 \\
• Behavior & & & & \\
Warning work effort & 26.7 & -4.7 & 3.0 & 1074 \\
Suspension, term 3 & 10.7 & -0.2 & 1.5 & 1070 \\
Truancy (number half days) & 16.0 & -0.5 & 0.8 & 1.031 \\
- End of middle school examination & & & & \\
Not registered & 4.2 & -1.1 & 1.0 & 1130 \\
Fail & 55.4 & +1.3 & 2.3 & 1130 \\
$\quad$ Fail. but present on exam day & 44.8 & $+6.7 * *$ & 2.5 & 1130 \\
$\quad$ Not present on exam day & 10.6 & $-5.4 * *$ & 1.3 & 1130 \\
Pass & 40.4 & -0.2 & 2.3 & 1130 \\
$\quad$ Honors & 1.9 & +1.2 & 1.0 & 1130 \\
\hline \hline
\end{tabular}

Note: Each row corresponds to a different model, based on administrative data. Column (C) shows the average value for the selected students in the control group. Column (T-C) contains the coefficient of a treatment class dummy. We use a linear probability model where we control for school dummies, first trimester average marks, gender, currently repeating dummy, low income dummy, as well as dummies for missing first trimester, and missing repeater. For behavior variables, the regression also includes a control for first trimester value. Column (se) shows corresponding standard error clustered at the class level. ${ }^{*}$ significant effects at the $10 \%$ level; ** at the $5 \%$ level. 
Table 4: Treatment effects on applications at the end of the treatment year, selected students

\begin{tabular}{llll}
\hline \hline List of applications includes... & C & T - C & se \\
\hline At least one 2-year vocational program & 15.8 & $+4.9^{* *}$ & 1.9 \\
2-year vocational is first choice & 11.0 & $+3.8^{* *}$ & 1.7 \\
2-year vocational is not first choice & 4.8 & +1.1 & 1.1 \\
No 2-year vocational nor 3-year academic & 61.0 & $-5.5^{* *}$ & 2.6 \\
programs & & & \\
Only 3-year vocational programs & 50.6 & -2.5 & 2.7 \\
Repetition or appeal & 10.4 & $-3.0^{*}$ & 1.6 \\
3-year academic program & 16.7 & +0.1 & 1.8 \\
Other cases (private. other districts) & 6.5 & +0.5 & 1.1 \\
\hline \hline
\end{tabular}

Note: Each row corresponds to a different model, based on administrative data. Column (C) shows the average value for the selected students in the control group. Column (T-C) contains the coefficient of a treatment class dummy. We use a linear probability model where we control for school dummies, first trimester average marks, year-long average marks, gender, currently repeating dummy, low income dummy, as well as dummies for missing first trimester and year-long marks, and missing repeater. The number of observations used is $\mathrm{N}=1130$. Column (se) shows corresponding standard error clustered at the class level. * significant effects at the $10 \%$ level; ** at the $5 \%$ level. 
Table 5: Treatment effect on assignment one year after treatment, selected students

\begin{tabular}{llll}
\hline \hline Status one year after intervention & C & T - C & se \\
\hline • Within national education & & & \\
3-year academic & 18,5 & $-0,0$ & 1,8 \\
3-year vocational & 50,4 & $+0,8$ & 2,9 \\
Repetition & 12,7 & $-3,5^{* *}$ & 1,6 \\
Repetition or appeal in the choice list & 6,5 & $-1,0$ & 1,3 \\
Repetition and appeal not in the list & 6,2 & $-2,5^{* *}$ & 1,0 \\
2-year vocational & 3,8 & $+3,3^{* *}$ & 1,1 \\
$\quad$ 2-year vocational in the choice list & 3,5 & $+2,1^{* *}$ & 1,0 \\
$\quad$ 2-year vocational not in the list & 0,4 & $+1,2^{* *}$ & 0,5 \\
Outside national education & & & 1,4 \\
Apprenticeship & 5,8 & $+3,1^{* *}$ & 1,1 \\
Dropout & 8,8 & $-3,7^{* *}$ & \\
\hline \hline
\end{tabular}

Note: Each row corresponds to a different model, based on administrative data. Column (C) shows the average value for the selected students in the control group. Column (T-C) contains the coefficient of a treatment class dummy. We use a linear probability model where we control for school dummies, first trimester average marks, year-long average marks, gender, currently repeating dummy, low income dummy, as well as dummies for missing first trimester and year-long marks, and missing repeater. The number of observations used is $\mathrm{N}=1130$. Column (se) shows corresponding standard error clustered at the class level. * significant effects at the $10 \%$ level; ** at the $5 \%$ level. 
Table 6: Treatment effects on assignment two years after treatment, selected students

\begin{tabular}{lclc}
\hline \hline Status two years after intervention & $\mathrm{C}$ & $\mathrm{T}-\mathrm{C}$ & $\mathrm{se}$ \\
\hline First year completed & 52.7 & $+4.4^{*}$ & 2.6 \\
3-year general $\left(2^{\text {nd }}\right.$ year) & 10.8 & +1.0 & 1.6 \\
3-year vocational (2 ${ }^{\text {nd }}$ year) & 38.7 & -0.0 & 2.7 \\
2-year vocational (2 ${ }^{\text {nd }}$ year) & 3.3 & $+3.4^{* *}$ & 1.0 \\
First year still not completed & 20.0 & -1.9 & 2.2 \\
3-year general (1st year) & 9.0 & -1.0 & 1.5 \\
3-year vocational (1st year) & 9.2 & -0.9 & 1.6 \\
2-year vocational (1st year) & 1.7 & -0.0 & 0.7 \\
Apprenticeship & 7.3 & +2.3 & 1.4 \\
Dropout & 20.0 & $-5.1^{* *}$ & 1.9 \\
dropout in year 1 & 7.5 & $-3.9^{* *}$ & 1.0 \\
repeating $9^{\text {th }}$ grade in year 1 & 2.3 & $-1.5^{* *}$ & 0.6 \\
others & 10.2 & +0.3 & 1.7 \\
\hline \hline
\end{tabular}

Note: Each row corresponds to a different model, based on administrative data. Column (C) shows the average value for the selected students in the control group. Column (T-C) contains the coefficient of a treatment class dummy. We use a linear probability model where we control for school dummies, first trimester average marks, year-long average marks, gender, currently repeating dummy, low income dummy, as well as dummies for missing first trimester and year-long marks, and missing repeater. The number of observations used is $\mathrm{N}=1130$. Column (se) shows corresponding standard error clustered at the class level. * significant effects at the $10 \%$ level; ** at the $5 \%$ level. 
Table 7: Spillover effects on non-selected students: marks and applications at the end of the treatment year

\begin{tabular}{|c|c|c|c|c|c|c|c|c|c|}
\hline & \multicolumn{3}{|c|}{ All } & \multicolumn{3}{|c|}{ Some friends selected } & \multicolumn{3}{|c|}{$\begin{array}{c}\text { Some friends selected } \\
\text { and pre-treatment marks }<=12\end{array}$} \\
\hline & $\mathrm{C}$ & $\mathrm{T}-\mathrm{C}$ & Obs. & $\mathrm{C}$ & $\mathrm{T}-\mathrm{C}$ & Obs. & $\mathrm{C}$ & $\mathrm{T}-\mathrm{C}$ & Obs. \\
\hline - Average marks (annual) & 124.1 & $-0.8(0.5)$ & 2913 & 117.4 & $-0.2(0.7)$ & 1183 & 96.7 & $+0.4(1.1)$ & 512 \\
\hline \multicolumn{10}{|l|}{ - Applications } \\
\hline Appeal or repetition & 3.1 & $+0.9(0.7)$ & 2972 & 4.3 & $+0.2(1.1)$ & 1208 & 9.2 & $-1.1(2.3)$ & 528 \\
\hline 3-year general & 73.2 & $-1.0(1.4)$ & 2972 & 67.7 & $-3.6(2.3)$ & 1208 & 38.7 & $-7.7(3.6)^{* *}$ & 528 \\
\hline 3-year vocational & 22.2 & $+0.0(1.4)$ & 2972 & 28.4 & $+2.4(2.3)$ & 1208 & 50.8 & $+8.7(3.8)^{* *}$ & 528 \\
\hline 2-year vocational & 6.2 & $-2.0(0.9)^{* *}$ & 2972 & 6.2 & $+0.3(1.3)$ & 1208 & 13.0 & $-2.2(2.6)$ & 528 \\
\hline Others & 5.1 & $+0.1(0.6)$ & 2972 & 3.4 & $+0.8(0.8)$ & 1208 & 5.5 & $+0.7(1.4)$ & 528 \\
\hline
\end{tabular}

Note: Each row corresponds to a different model, based on administrative data. Column (C) shows the average value for the non-selected students in the control group. Column (T-C) contains the coefficient of a treatment class dummy, with corresponding standard-error in parenthesis (clustered at the class level). Friends are measured as of baseline. We use a linear probability model where we control for school dummies, first trimester average marks, year-long average marks, gender, currently repeating dummy, low income dummy, as well as dummies for missing first trimester and year-long marks, and missing repeater. * significant effects at the $10 \%$ level; ** at the $5 \%$ level. 
Table 8: Spillover effects on non-selected students: assignment one and two years after treatment

\begin{tabular}{|c|c|c|c|c|c|c|}
\hline & \multicolumn{2}{|r|}{ All } & \multicolumn{2}{|c|}{ Some friends selected } & \multicolumn{2}{|c|}{$\begin{array}{c}\text { Some friends selected } \\
\text { and pre-treatment } \\
\text { marks }<=12\end{array}$} \\
\hline & $\mathrm{C}$ & $\mathrm{T}-\mathrm{C}$ & $\mathrm{C}$ & $\mathrm{T}-\mathrm{C}$ & $\mathrm{C}$ & $\mathrm{T}-\mathrm{C}$ \\
\hline \multicolumn{7}{|l|}{$\begin{array}{l}\text { - Status one year after } \\
\text { treatment }\end{array}$} \\
\hline Repetition & 2.7 & $+0.5(0.6)$ & 3.9 & $-0.5(1.0)$ & 8.8 & $-1.3(2.3)$ \\
\hline 3-year academic track & 73.6 & $-2.0(1.4)$ & 67.9 & $-4.1(2.3)^{*}$ & 39.9 & $-7.4(3.4)^{* *}$ \\
\hline Vocational tracks & 19.5 & $+0.8(1.5)$ & 24.1 & +3.8 $(2.2)^{*}$ & 45.0 & $+9.2(3.9)^{* *}$ \\
\hline Dropouts & 4.2 & $+0.8(0.7)$ & 4.1 & $+0.7(1.1)$ & 6.3 & $-0.1(1.9)$ \\
\hline \multicolumn{7}{|l|}{$\begin{array}{l}\text { - Status two years after } \\
\text { treatment }\end{array}$} \\
\hline 3-year academic track & 70.3 & $-1.0(1.5)$ & 65.7 & $-3.2(2.4)$ & 38.2 & $-4.5(3.8)$ \\
\hline Vocational tracks $^{(1)}$ & 20.6 & $+1.7(1.5)$ & 26.9 & $+2.8(2.3)$ & 49.6 & $+7.0(4.1)$ \\
\hline Dropouts & 9.1 & $-0.7(0.9)$ & 7.5 & $+0.4(1.4)$ & 12.2 & $-2.5(2.4)$ \\
\hline Obs. & & 2972 & & 1208 & & 528 \\
\hline
\end{tabular}

Note: Each row corresponds to a different model, based on administrative data. Column (C) shows the average value for the non-selected students in the control group. Column (T-C) contains the coefficient of a treatment class dummy. We use a linear probability model where we control for school dummies, first trimester average marks, year-long average marks, gender, currently repeating dummy, low income dummy, as well as dummies for missing first trimester and year-long marks, and missing repeater. Column (se) shows corresponding standard error clustered at the class level. * significant effects at the $10 \%$ level; ** at the $5 \%$ level.

(1) includes second repetition of $9^{\text {th }}$ grade. 
Table 9: Treatment effects on the size and composition of friendship networks, selected students

\begin{tabular}{|c|c|c|c|}
\hline & Mean C & $\mathrm{T}-\mathrm{C}$ & Se \\
\hline \multicolumn{4}{|l|}{ - Network stability } \\
\hline Persistent friends & 41.0 & $+10.4^{* *}$ & 3.4 \\
\hline Persistent and selected & 13.9 & $+6.2 * *$ & 2.8 \\
\hline Persistent and non-selected & 27.1 & +4.2 & 2.9 \\
\hline Friends lost & 66.1 & $-12.4^{* *}$ & 5.5 \\
\hline New friends & 47.0 & $-6.8^{*}$ & 3.7 \\
\hline \multicolumn{4}{|l|}{ - Network size } \\
\hline \multicolumn{4}{|l|}{ Final network (june 2011) } \\
\hline Number of friends & 2.72 & -.08 & .15 \\
\hline 0 friend & 15.5 & $-6.0 * *$ & 2.7 \\
\hline 1-3 friends & 47.8 & $+13.7 * *$ & 4.3 \\
\hline 4-5 friends & 36.6 & $-7.7 *$ & 4.1 \\
\hline \multicolumn{4}{|l|}{ Initial network (october 2010) } \\
\hline Number of friends & 2.97 & +.22 & .20 \\
\hline 0 friend & 5.6 & -2.8 & 2.2 \\
\hline 1-3 friends & 55.6 & +0.9 & 6.2 \\
\hline 4-5 friends & 38.8 & +1.9 & 6.6 \\
\hline \multicolumn{4}{|l|}{ • Network composition } \\
\hline \multicolumn{4}{|l|}{ Final network (june 2011) } \\
\hline Selected friends & 30.9 & +1.4 & 3.5 \\
\hline Treated friends & 1.6 & $+18.6 * *$ & 2.5 \\
\hline Friends who will repeat or dropout & 10.7 & $-5.4 * *$ & 1.8 \\
\hline Friends who will enrol 2-year program & 3.3 & $+4.8^{* *}$ & 1.9 \\
\hline Friends who will enrol 3-year program & 69.6 & $+7.8^{* *}$ & 3.6 \\
\hline Has gained a future dropout/repeaters & 14.7 & $-7.1^{*}$ & 3.6 \\
\hline Has lost a future dropout/repeaters & 12.5 & -4.1 & 2.8 \\
\hline \multicolumn{4}{|l|}{ Initial network (october 2010) } \\
\hline Selected friends & 34.6 & +4.0 & 3.8 \\
\hline Treated friends & 1.8 & $+18.4^{* *}$ & 2.1 \\
\hline Friends who will repeat or dropout & 12.0 & $-4.2^{*}$ & 2.3 \\
\hline Friends who will enrol 2-year program & 3.6 & $+5.3^{* *}$ & 1.9 \\
\hline Friends who will enrol 3-year program & 77.6 & +2.2 & 3.1 \\
\hline
\end{tabular}

Note: Each row corresponds to a different model, based on networks survey data. The analysis is restricted to classes for which friendship surveys have been filled both at baseline and endline. Column (C) shows the average value for the non-selected students in the control group. Column (T-C) contains the coefficient of a treatment class dummy. We use a linear probability model where we control for school dummies, first trimester average marks, gender, currently repeating dummy, low income dummy, as well as dummies for missing first trimester, and missing repeater. For network stability variables, the regression also includes number of friends in first trimester. For final network size variables, the regression also includes a control for first trimester value. Column (se) shows corresponding standard error clustered at the class level. The number of observations used is $\mathrm{N}=524$. * significant effects at the $10 \%$ level; ** at the $5 \%$ level. 
Table 10: Class-level analysis of the effect of selected students' aspirations and parents' expectations on students' dropout rates one year after treatment

\begin{tabular}{|c|c|c|c|}
\hline \multirow[t]{2}{*}{ Panel A } & \multirow{2}{*}{$\begin{array}{l}\text { Proportion students } \\
\text { with unrealistic } \\
\text { aspirations } \\
\text { (First stage) }\end{array}$} & \multicolumn{2}{|c|}{$\begin{array}{c}\text { Proportion of students } \\
\text { who drop out one year } \\
\text { after treatment }\end{array}$} \\
\hline & & $\begin{array}{l}\text { (Reduced } \\
\text { form) }\end{array}$ & (IV) \\
\hline Treatment & $\begin{array}{c}-0.061 * * \\
(0.026)\end{array}$ & $\begin{array}{c}-0.035^{* *} \\
(0.013)\end{array}$ & - \\
\hline $\begin{array}{l}\text { Proportion students with } \\
\text { unrealistic aspirations }\end{array}$ & - & - & $\begin{array}{l}+0.58 \\
(0.38)\end{array}$ \\
\hline Obs. & 179 & 179 & 179 \\
\hline \multirow[t]{2}{*}{ Panel B } & $\begin{array}{l}\text { Proportion parents } \\
\text { with over-optimistic } \\
\text { expectations }\end{array}$ & \multicolumn{2}{|c|}{$\begin{array}{l}\text { Proportion of students } \\
\text { who dropout one year } \\
\text { after treatment }\end{array}$} \\
\hline & (First stage) & $\begin{array}{l}\text { (Reduced } \\
\text { form) }\end{array}$ & (IV) \\
\hline Treatment & $\begin{array}{c}-0.078 * * \\
(0.035)\end{array}$ & $\begin{array}{c}-0.038^{* *} \\
(0.013)\end{array}$ & - \\
\hline $\begin{array}{l}\text { Proportion parents with } \\
\text { over-optimistic expectations }\end{array}$ & - & - & $\begin{array}{c}+0.49^{*} \\
(0.29)\end{array}$ \\
\hline Obs. & 178 & 178 & 178 \\
\hline
\end{tabular}

Note: Panel A shows the instrumental variable (IV) regression of the proportion of selected student who drop out from school one year after the treatment on the proportion of selected students with unrealistic aspiration at the end of the treatment year using treatment status as an instrument. This is estimated on selected students at the class level to account for spillovers. Unrealistic aspiration is measured by students whose list of applications includes grade repetition or 3-year programs only (no 2-year programs). The first column shows the results of the first-stage regression of the proportion with unrealistic aspirations on the instrument, whereas the second column shows the reduced form regression of the dependent variable (proportion of dropout) on the instrument (treatment status). Panel B shows a similar IV regression analysis using the proportion of parents with overoptimistic expectations as basic dependent variable. Over-optimistic expectation is measured by parents expecting that their child will graduate from a 3-year program. In all regressions, we control for school fixed effects as well as for a set of class-level variables describing selected students' baseline characteristics: proportion of boys, proportion from low income families, proportion of grade repeaters, first term average marks, annual average marks, proportion with annual average marks less than 10/20 (as well the proportions with missing information on first-term average marks, annual average marks or grade repetitions). One class has missing information on selected parents' expectations, this is why the number of observation is 178 in panel B and 179 in panel A. * significant effects at the $10 \%$ level; ** at the $5 \%$ level. 
APPENDIX 
Appendix Table A1: Baseline comparison of selected students in test and control classes and differential response rates

\begin{tabular}{lcccc}
\hline \hline $\begin{array}{l}\text { Variables available for the full sample } \\
\text { Selected students }\end{array}$ & C & T-C & se & Obs. \\
\hline Girls & 44.2 & -0.8 & 2.5 & 1130 \\
Has already repeated a grade & 54.4 & -0.4 & 2.4 & 1130 \\
Low income & 32.3 & 0.9 & 2.6 & 1130 \\
\hline \hline
\end{tabular}

\section{Differential response rates at various surveys and for administrative data}

Survey parents (selected students)

General information meetings (parents)

Indiv. meetings with career consellor (parents)

Indiv. meeting with teachers (parents)

Has attended meetings of parents' orga (parents)

Has talked with other parents (parents)

Happy with school info (parents)

Expected diploma (parents)

School data (selected students)

Annual average marks

Average marks, term 3

Warning work effort, term 3

Suspension, term 3

Truancy, term 3

Survey on networks

Tables 7 and 8 (full sample)

Tables 7 and 8 (some friends selected)

Tables 7 and 8 (some friends selected and Marks<12)

Table 9

C T-C se Obs

Obs

\begin{tabular}{|c|c|c|c|}
\hline 74.6 & -1.3 & 2.6 & 1130 \\
\hline 74.6 & -0.9 & 2.5 & 1130 \\
\hline 75.8 & -2.4 & 2.4 & 1130 \\
\hline 75.0 & -2.2 & 2.6 & 1130 \\
\hline 74.6 & -2.0 & 2.6 & 1130 \\
\hline 75.0 & -1.8 & 2.5 & 1130 \\
\hline 74.4 & -1.5 & 2.5 & 1130 \\
\hline 97.1 & -0.2 & 0.9 & 1130 \\
\hline 94.4 & -2.5 & 2.0 & 1130 \\
\hline 95.0 & -0.2 & 1.3 & 1130 \\
\hline 95.0 & -0.8 & 1.5 & 1130 \\
\hline 92.7 & -1.3 & 0.9 & 1130 \\
\hline 92.0 & $3.3^{*}$ & 2.0 & 3161 \\
\hline 36.8 & 3.4 & 3.2 & 3161 \\
\hline 16.3 & 1.3 & 1.7 & 3161 \\
\hline 44.6 & -0.2 & 5.1 & 1130 \\
\hline
\end{tabular}

Note: Each row corresponds to a different model, based on administrative data. Column (C) shows the average value for the non-selected students in the control group. Column (T-C) contains the coefficient of the treatment dummy. We use a linear probability model where we control for school dummies. 
Appendix Table A2: Treatment effect on the share and composition of selected students that remain in the national education system

\begin{tabular}{lcccc}
\hline \hline & C & T-C & s.e. & Obs \\
\hline Stays within the education system & 85.4 & +0.6 & 1.6 & 1130 \\
Composition of the group : & & & & \\
Boys (\%) & 55.4 & +0.6 & 2.8 & 971 \\
Has just repeated 9th grade(\%) & 6.8 & -0.7 & 1.7 & 971 \\
Annual average marks (/200) & 87.5 & +0.7 & 0.9 & 971 \\
Low income parents (\%) & 32.9 & +1.7 & 2.9 & 971 \\
First term marks (/20) & 9.32 & -0.04 & 0.08 & 971 \\
\hline \hline
\end{tabular}

Note: Each row corresponds to a different model, based on administrative data. Column (C) shows the average value for the non-selected students in the control group. Column (T-C) contains the coefficient of the treatment dummy. We use a linear probability model where we control for school dummies, and, if the variable is not the dependent one, for first trimester average marks, year-long average marks, gender, currently repeating dummy, low income dummy, as well as dummies for missing first trimester and year-long marks, and missing repeater. Column (se) shows corresponding standard error clustered at the class level. * significant effects at the $10 \%$ level; ** at the 5\% level. 
Appendix Table A3: Effect on marks and assignment at the end of the last 9th grade, selected students

\begin{tabular}{lcccc}
\hline \hline & C & T - C & se & Obs. \\
\hline - Marks : & & & & \\
Average marks (/240) & 87.7 & +0.6 & 0.9 & 1102 \\
Prop. whose average marks>110 & 14.9 & +0.9 & 2.0 & 1102 \\
- Assignment & & & & \\
3-year general & 22.7 & -0.9 & 2.0 & 1130 \\
3-year vocational & 55.0 & -0.3 & 2.7 & 1130 \\
2-year vocational & 4.4 & $+3.3^{* *}$ & 1.1 & 1130 \\
Apprenticeship & 6.7 & +2.3 & 1.5 & 1130 \\
Dropout & 11.2 & $-4.8^{* *}$ & 1.4 & 1130 \\
Other & 0.0 & +0.4 & 0.3 & 1130 \\
\hline \hline
\end{tabular}

Note: Each row corresponds to a different model, based on administrative data. Column (C) shows the average value for the non-selected students in the control group. Column (T-C) contains the coefficient of the treatment dummy. We use a linear probability model where we control for school dummies, first trimester average marks, gender, currently repeating dummy, low income dummy, as well as dummies for missing first trimester and yearlong marks, and missing repeater. For assignment variables we add two more controls: year-long average marks and a dummy for missing year-long average marks. Column (se) shows corresponding standard error clustered at the class level. * significant effects at the $10 \%$ level; ** at the $5 \%$ level. 
Appendix Table A4: Friendship networks: descriptive statistics

\begin{tabular}{|c|c|c|}
\hline & Mean & $\begin{array}{l}\text { Standard } \\
\text { deviation }\end{array}$ \\
\hline \multicolumn{3}{|l|}{ Respondents' own characteristics } \\
\hline Boys (\%) & 49.1 & 50.0 \\
\hline Selected (\%) & 26.4 & 44.1 \\
\hline Already repeated a grade (\%) & 31.7 & 46.5 \\
\hline \multicolumn{3}{|c|}{ Characteristics of respondents' friendship networks } \\
\hline Number of friends & 2.66 & 1.45 \\
\hline No friends & 7.2 & 25.9 \\
\hline \multicolumn{3}{|l|}{ Proportion of friends with same sex as respondent } \\
\hline For girls & 89.6 & 23.0 \\
\hline For boys & 88.9 & 24.9 \\
\hline \multicolumn{3}{|c|}{ Proportion of friends with same selection status as respondent } \\
\hline For selected students & 35.9 & 33.9 \\
\hline For non selected students & 77.6 & 29.9 \\
\hline \multicolumn{3}{|c|}{$\begin{array}{l}\text { Proportion of friends with same grade repetition status as } \\
\text { respondent }\end{array}$} \\
\hline For students who have repeated a grade & 41.2 & 34.8 \\
\hline For students who have not repeated a grade & 74.5 & 32.0 \\
\hline
\end{tabular}

Note: The sample of respondents with information on friendship network has 4,040 observations. The average proportion of friends with same sex (or same selection status, or same grade repetition status) are computed on the sample of respondents with at least one friend ( $N=3,748)$. Reading: $49.1 \%$ of respondents with information on friendship networks are boys. For those who have at least one friend, the proportion of boys among their friends is $88.9 \%$. 


\section{Appendix B: Wage value of the intervention}

The broad picture about the intervention under consideration is that it reduces dropout upon entering high-school by $25 \%$ at a two year horizon, among the low performing students who are the most at risk of dropout (from 20\% to 15\%). As a counterpart, it increases students in 2-year vocational education and apprenticeship by 3.4 and 2.3 percentage points respectively in this population. Appendix Table B1 helps understand the value of this intervention: using the Labour Force Survey conducted in 2011, it shows that the unemployment rate of high-school dropouts (42\%) is almost twice as large as those of students who completed a 2-year vocational program and about three times as large as that those of students who completed a 3-year vocational program. ${ }^{24}$ Among high-school dropouts, those who drop out early (before completing the first years of their program) are faced with even higher unemployment rate (49\%) than those who dropout after completing the first years of their program (36\%). Similarly, the earnings difference between dropouts and individuals who completed 2-year vocational education or apprenticeship is $19 \%$ or $25 \%$. Overall, at the end of middle-school, many low-achieving students end up dropping out from education even though this decision is associated with very poor labour market outcomes. Specifically, very few students choose apprenticeship, even though former apprentices tend to perform better on the labour market than former vocational schools' students with similar diplomas (Abriac et al. 2009).

Combining that same labour force data and the estimated impact of our program, we can compute wage returns to the intervention. We use average wages received during the 1-3

\footnotetext{
${ }^{24}$ Some 2-year vocational specialties (such as sale or tourism) are associated with higher unemployment risks than other specialities (such as electricity or mechanics), but none is associated with unemployment risks that are as high as those faced by dropouts (see detailed analysis by specialties in Martinelli and Prost, 2010).
} 
years and the 4-6 years after entering the labor market, assuming that each student stops school at the end of her chosen track (2-year vocational after they obtain the corresponding diploma, 3-year academic after they obtain the Baccalauréat, etc.). This underestimates the wage impact because it doesn’t include the option value of pursuing education. We count zero earnings for those who do not work or are unemployed, which is a reasonable approximation for the young dropouts who are rarely eligible to unemployment benefits and not eligible for welfare support before the age of 25 . We find that the average wage in the treatment group is increased by $2.7 \%$ (s.e. 1.5 ) after $1-3$ years of experience and by $2.9 \%$ (s.e. 1.4 ) after $4-6$ years. Notice that much of this impact is related to lower exposure to unemployment: the treatment would decrease unemployment on average by 1.06 points (out of 28\%) 1-3 years after entry on the labor market and by 1.27 points (out of 19\%) 4-6 years after entry.

Naturally, one can wonder whether the direct comparison of average wages of young dropouts and young graduates of 2-year vocational education do measure the returns for the margin of the population of selected students who are affected by our program. The general impression from the literature is that OLS returns to schooling are generally lower than LATE returns estimated on the margins of students that are impacted by policies that make potential dropouts stay longer in school, such as longer compulsory education (Card, 2001, Oreopoulos, 2006 and 2007). Maurin and Xenogiani (2007) report similar findings for France. ${ }^{25}$ Although we are not aware of comparable estimates for the specific returns to vocational education, there is no a priori reason to believe that OLS-like computations would strongly overestimate the wage returns of our program on the affected population.

\footnotetext{
${ }^{25}$ Building on the fact that the 1997 abolition of compulsory conscription in France was followed by a drop in the proportion of male students pursuing secondary education after age 17 (because conscription induced incentives to graduate from high-school), Maurin and Xenogiani (2007) reports estimates of the causal effect of completing one additional year of secondary education that are as large the differential observed in cross section between more and less educated male workers (about $+15 \%$ in annual earnings per additional year of secondary education).
} 
Appendix Table B1: Unemployment and wages at entry into the labour market, by education groups.

\begin{tabular}{lccc}
\hline \hline & Unemployment & Monthly earnings \\
\hline 3-year general & 10.6 & 1650 & 172 \\
3-year vocational & 18.0 & 1260 & 131 \\
2-year vocational & 27.0 & 1100 & 115 \\
& 16.6 & 1300 & 136 \\
Apprenticeship & 19.8 & 1250 & 130 \\
2-year vocational & 10.2 & 1390 & 144 \\
3-year vocational & 43.5 & 1070 & 111 \\
& 37.2 & 1160 & 122 \\
Dropout & 50.6 & 960 & 100 \\
Late dropout & & & \\
Early dropout & & & \\
\hline
\end{tabular}

Source: French Labor Force Survey conducted in 2011. Note: The Table reports the average unemployment rate and average monthly earnings of wage-earner with 1-5 years of labour market experience. 